\title{
Planar perovskite solar cells with long-term stability using ionic liquid additives
}

Sai Bai, Peimei Da, Cheng Li, Zhiping Wang, Zhongcheng Yuan, Fan Fu, Maciej Kawecki, Xianjie Liu, Nobuya Sakai, Jacob Tse-Wei Wang, Sven Huettner, Stephan Buecheler, Mats Fahlman, Feng Gao and Henry J. Snaith

The self-archived postprint version of this journal article is available at Linköping University Institutional Repository (DiVA):

http://urn.kb.se/resolve?urn=urn:nbn:se:liu:diva-159145

N.B.: When citing this work, cite the original publication.

The original publication is available at www.springerlink.com:

Bai, S., Da, P., Li, C., Wang, Z., Yuan, Z., Fu, F., Kawecki, M., Liu, X., Sakai, N., Wang, J. T., Huettner, S., Buecheler, S., Fahlman, M., Gao, F., Snaith, H. J., (2019), Planar perovskite solar cells with long-term stability using ionic liquid additives, Nature, 571(7764), 245-250. https://doi.org/10.1038/s41586-019-1357-2

Original publication available at:

https://doi.org/10.1038/s41586-019-1357-2

Copyright: Nature Research (part of Springer Nature)

http://www.nature.com/ 


\section{Planar perovskite solar cells with long-term stability using ionic liquid additives}

Sai Bai, ${ }^{1,2}$ Peimei Da, ${ }^{1}$ Cheng $\mathrm{Li}^{3},{ }^{3}$ Zhiping Wang, ${ }^{1}$ Zhongcheng Yuan, ${ }^{2}$ Fan $\mathrm{Fu},{ }^{4}$ Maciej Kawecki, ${ }^{5,6}$ Xianjie Liu, ${ }^{2}$ Nobuya Sakai, ${ }^{1}$ Jacob Tse-Wei Wang, ${ }^{7}$ Sven Huettner, ${ }^{3}$ Stephan Buecheler, ${ }^{4}$ Mats Fahlman, ${ }^{2}$ Feng Gao ${ }^{2,1}$ \& Henry J. Snaith ${ }^{1}$

${ }^{1}$ Clarendon Laboratory, University of Oxford, Parks Road, Oxford, OX1 3PU, UK

${ }^{2}$ Department of Physics, Chemistry and Biology (IFM), Linköping University, Linköping, SE-581 83, Sweden

${ }^{3}$ Department of Chemistry, University of Bayreuth, Universitätstr. 30, 95447 Bayreuth, Germany

${ }^{4}$ Laboratory for Thin Films and Photovoltaics, Empa-Swiss Federal Laboratories for Materials Science and Technology, Ueberlandstrasse 129, 8600 Duebendorf, Switzerland ${ }^{5}$ Laboratory for Nanoscale Materials Science, Empa, CH-8600 Dubendorf, Switzerland ${ }^{6}$ Department of Physics, University of Basel, CH-4056 Basel, Switzerland ${ }^{7}$ CSIRO Energy, Mayfield West, NSW 2304, Australia 
Metal halide perovskite solar cells are emerging as one of the most promising future photovoltaic (PV) technologies ${ }^{1-4}$. Compositional tuning of perovskites ${ }^{5-9}$, interface engineering of device structures ${ }^{10-13}$, and encapsulation techniques ${ }^{14,15}$ have significantly advanced the long-term operational stability over the last few years. However, much further improvements are still required to deliver a 25-year stable technology. Ion migration in the perovskite active layer, especially under light illumination and heat, is arguably the most difficult aspect to mitigate ${ }^{16-18}$. Here we incorporate ionic liquids into the perovskite film and "positive-intrinsic-negative" (p-i-n) PV devices, and demonstrate both a notable increase in efficiency and remarkable enhancement in long-term stability. We observe $\sim 5 \%$ degradation of encapsulated devices under continuous simulated full-spectrum sunlight for over 1,800 hours at an elevated temperature of $\sim 70$ to $75{ }^{\circ} \mathrm{C}$ and estimate a $T_{80}$ lifetime (time to $80 \%$ of its peak performance) of $\sim 5,200$ hours. This demonstration of long-term operational stable solar cells under intense conditions represents a key step towards ensuring reliability of the perovskite PV technology.

Ionic liquids (ILs) have been previously incorporated into negative-intrinsic-positive (n-i-p) perovskite solar cells and shown improved device performance ${ }^{19,20}$. The mechanism driving the improvements has been ascribed to the formed halide complexes $^{20}$ or an advantageous energy level alignment at the n-type charge extraction layer/perovskite interface $^{19}$. Here we incorporate an IL-containing triple-cation perovskite absorber of $\left(\mathrm{FA}_{0.83} \mathrm{MA}_{0.17}\right)_{0.95} \mathrm{Cs}_{0.05} \mathrm{~Pb}\left(\mathrm{I}_{0.9} \mathrm{Br}_{0.1}\right)_{3}{ }^{5}$, where $\mathrm{FA}$ is formamidinium and $\mathrm{MA}$ is methylammonium, into p-i-n planar solar cells, employing $\mathrm{NiO}$ and [6,6]-phenyl- $\mathrm{C}_{61}$-butyric acid methyl ester (PCBM) as the p- and n-type charge extraction layers, respectively (Fig. 1a).

We add 1-butyl-3-methylimidazolium tetrafluoroborate $\left(\mathrm{BMIMBF}_{4}\right)(\mathrm{Fig}$. 1b) to the perovskite precursor, and observe enhanced efficiencies in complete PV cells, with 0.15 to $0.9 \mathrm{~mol} \%$ of $\mathrm{BMIMBF}_{4}$ with respect to the $\mathrm{Pb}$ (Extended Data Fig. 1a to 1e). When we measure the devices, we notice improved performance due to initial light soaking during the 
current-voltage $(J-V)$ measurements, which we elaborate upon in Extended Data Fig. 1f and 1e. The steady-state power output (SPO) is measured at a fixed voltage near the maximum power point (MPP) from the peak $J-V$ curves for $50-100 \mathrm{~s}$ of the top one or two best-performing devices of each substrate. For the champion device with $0.3 \mathrm{~mol} \%$ $\mathrm{BMIMBF}_{4}$, we measure an open-circuit voltage $\left(V_{\mathrm{OC}}\right)$ of $1.08 \mathrm{~V}$, a short-circuit current $\left(J_{\mathrm{SC}}\right)$ of $23.8 \mathrm{~mA} \mathrm{~cm}^{-2}$ and a high fill factor (FF) of 0.81 , yielding a power conversion efficiency (PCE) of 19.8\% (Fig.1c and Extended Data Table 1, measurement is made under $105 \mathrm{mWcm}^{-2}$ irradiance). The champion control device exhibits a PCE of $18.5 \%$, due to a lower $V_{\mathrm{OC}}$ of $1.02 \mathrm{~V}$ and FF of 0.79 . We provide histograms of the PCEs of control and devices with 0.3 mol\% BMIMBF 4 in Fig. 1 d. We verify that $J_{\mathrm{SC}}$ derived from the $J-V$ curves are well matched with the external quantum efficiency (EQE) results, integrated over the solar spectrum (Fig.1e). We note that although we obtain devices with a small degree of $J-V$ hysteresis with careful optimization (Extended Data Fig. 1h), we do notice some hysteresis in our devices, but measure an SPO of $18.7 \%$ and $20.0 \%$ for the champion device of control and that with optimal $\mathrm{BMIMBF}_{4}$, respectively (Fig. 1f). We observe increased hysteresis in $\mathrm{BMIMBF}_{4}$-containing devices with increasingly higher concentration of $\mathrm{BMIMBF}_{4}$ in the perovskite film. A pronounced hysteresis and an abnormal "overshoot" close to maximum power point in the $J-V$ curve appear when $1.2 \mathrm{~mol}^{\circ} \mathrm{BMIMBF}_{4}$ is incorporated into the perovskite active layer. (Extended Data Fig 1i).

In order to understand why the addition of a low concentration of $\mathrm{BMIMBF}_{4}$ has improved the device performance, we perform a range of film characterizations. With the addition of $\mathrm{BMIMBF}_{4}$, the X-ray diffraction (XRD) peak positions remain unaltered, consistent with neither $[\mathrm{BMIM}]^{+}$nor $\left[\mathrm{BF}_{4}\right]^{-}$incorporating into and perturbing the perovskite crystal lattice (Extended Data Fig. 2a). However, a slightly increased intensity of the main diffraction peaks occurs, suggesting enhanced texturing or crystallinity, in good agreement with the slightly enlarged grains in the scanning electron microcopy (SEM) images (Extended Data Fig. 2b). We find negligible change in the film absorption but observe increased photoluminescence $(\mathrm{PL})$ intensity and extended $\mathrm{PL}$ lifetime for the $\mathrm{BMIMBF}_{4}$-containing 
perovskite film (Extended Data Fig. 2c and 2d), which is consistent with reduced defects in the film.

We perform ultraviolet photoelectron spectroscopy (UPS) and X-ray photoelectron spectroscopy (XPS) to investigate the surface electronic properties of the perovskite films. From the UPS spectra, we observe a $320 \mathrm{meV}$ decrease in the work-function (WF) of perovskite film from 5.13 to $4.81 \mathrm{eV}$ with respect to vacuum, after addition of $\mathrm{BMIMBF}_{4}$ (Extended Data Fig. 2e). There is no change in the relative Fermi level position with respect to the valance band offset, which indicates that the energy levels of the perovskite absorber have moved closer to vacuum, when processed with the $\mathrm{BMIMBF}_{4}$. The change on the energy level structure could result from a shift in the relative energy alignment of the buried heterojunction between the perovskite and the $\mathrm{NiO}$ hole-extraction layer, or a shift in energy level alignment at the topmost perovskite surface, which in a complete device will subsequently contact the PCBM electron-extraction layer. In light of the increased $V_{\mathrm{OC}}$ and FF in the cells, this resulting energetic shift is most likely leading to an improved energetic alignment, with smaller voltage losses at one or both of the heterojunctions, and improved charge extraction ${ }^{21}$.

From XPS spectra of the BMIMBF 4 -containing perovskite film (Fig. 2a), we detect the nitrogen $(\mathrm{N})$ of $\mathrm{BMIM}$ at $402.3 \mathrm{eV}$ but no fluorine $(\mathrm{F})$ of $\mathrm{BF}_{4}$ at $686.2 \mathrm{eV}$ from the top surface. We note that the signal strength for the F1s is usually stronger than that of the N1s, thus our results suggest that there is a predominant presence of BMIM at the top surface. This is also consistent with the energetic shifts being due to the organic cation modifying the surface dipole of the perovskite film.

We perform time-of-flight secondary ion mass spectrometry (ToF-SIMS) to probe the chemical composition throughout the film and present both the negative and positive ion signals. In the $\mathrm{BMIMBF}_{4}$-containing perovskite film, the $\mathrm{BF}_{4}$ is mainly located at the buried interface (Fig. 2b), while the BMIM exists throughout the bulk film in addition to accumulating at the buried interface (Fig. 2c). This suggests that there is an accumulation of ion pairs of $\mathrm{BMIM}$ and $\mathrm{BF}_{4}$, at the perovskite/NiO interface. We note that if we substitute the 
$\mathrm{NiO}$ for an organic hole-conductor, poly [N,N'-bis(4-butylphenyl)-N,N'-bis(phenyl)benzidine] (poly-TPD), we measure decreased efficiencies with obvious hysteresis and the emergence of an overshoot in the $J-V$ curve from devices with 0.3 mol\% $\mathrm{BMIMBF}_{4}$ (Extended Data Fig. 3). This indicates that the mechanism driving the enhanced device performance in the NiO-based cells here, is related to the improved interaction between perovskite and $\mathrm{NiO}$ at the interface ${ }^{22}$, facilitated by processing with the BMIMBF 4 .

We characterize the PL of perovskite thin films in-between two in-plane electrodes, with a constant electrical bias applied between the electrodes, to determine if there are any fieldor ion-induced changes in the $\mathrm{BMIMBF}_{4}$-containing perovskite films ${ }^{17,23}$. In the series of PL images of the films as a function of time (Fig. 2d), we observe clear luminescence quenching from the positive toward the negative electrode for the control film. We interpret that the PL is suppressed by the ion migration, where some regions of the film accumulate a high density of defects and/or the stoichiometry of the perovskite layer deviates considerably at different positions across the channel between the electrodes ${ }^{24}$. In stark contrast, for the $\mathrm{BMIMBF}_{4}$-containing perovskite film, the $\mathrm{PL}$ is close to unchanging throughout the entire measurement time. Unpredictably, our observations indicate significantly suppressed ion migration in the perovskite films by introducing $\mathrm{BMIMBF}_{4}$.

We now investigate the stability of perovskite films under simulated full-spectrum sunlight at $60-65{ }^{\circ} \mathrm{C}$ in ambient air. For the control film, we observe an obvious colour change from black to yellow-grey after $72 \mathrm{~h}$ of light-soaking, which is due to a fractional decomposition to $\mathrm{PbI}_{2}$, as we infer from XRD measurements (Fig. 3a). We expect this to happen, since in the presence of light and oxygen, superoxide is generated, which has been observed to rapidly decompose $\mathrm{MAPbI}_{3}{ }^{25,26}$. In contrast, we observe no discolouration and negligible $\mathrm{PbI}_{2}$ in the post-aged $\mathrm{BMIMBF}_{4}$-containing perovskite films.

In order to understand which components of the IL, $[\mathrm{BMIM}]^{+}$or $\left[\mathrm{BF}_{4}\right]^{-}$, are important for improving the device efficiency and the film stability, we assess the impact of a range of different ionic additives. We firstly characterize devices with the addition of $\mathrm{FABF}_{4}$ and obtain comparable efficiencies to the control (Extended data Fig. 4a), and observe no 
improvement in the film stability (Fig. $3 b$ and Extended Data Fig. 4b). By replacing the $\left[\mathrm{BF}_{4}\right]^{-}$, with halide $(X)$ anions, e.g. $\left(\mathrm{I}^{-}, \mathrm{Br}^{-}, \mathrm{Cl}^{-}\right)$, and retaining the $[\mathrm{BMIM}]^{+}$cation, we replicate the stability improvement of the perovskite films (Fig. $3 \mathrm{~b}$ and Extended Data Fig. 4b), but measure a significant decrease in the device efficiency (Extended data Fig. 4a). This indicates that both $[\mathrm{BMIM}]^{+}$and $\left[\mathrm{BF}_{4}\right]^{-}$are required to improve the film stability while simultaneously enhancing the device efficiency.

In order to elucidate the differences between the addition of $\mathrm{BMIMBF}_{4}$, and BMIMX, we investigate the interaction between $\mathrm{PbI}_{2}$ and the BMIM-based ILs. From photographs of the $\mathrm{PbI}_{2}$ :IL films, we observe retained yellow colouration of $\mathrm{PbI}_{2}$ for the $\mathrm{PbI}_{2}: \mathrm{BMIMBF}_{4}$ film, while all the $\mathrm{PbI}_{2}$ :BMIMX samples are optically transparent (Fig. 3c), suggesting the formation of lead halide-imidazolium halide complex. We find further evidence for the $\mathrm{PbI}_{2}$ :BMIMX complexes in the corresponding film absorption and XRD results (Fig. $3 \mathrm{~d}$ and 3e), where all our investigated BMIM-based ILs greatly suppress the emergence of crystalline $\mathrm{PbI}_{2}$.

As a further probe of the difference between the ILs with the halide anions, as compared to $\left[\mathrm{BF}_{4}\right]^{-}$, we interrogate the compositional distribution of halide throughout the BMIMCl-containing perovskite film. According to the ToF-SIMS results, the $\mathrm{Cl}^{-}$distributes throughout the thickness of the film (Fig. 3f), which is distinctly different from that of the $\left[\mathrm{BF}_{4}\right]^{-}$(Fig 2b), indicating that if $\mathrm{PbI}_{2}: \mathrm{BMIMX}$ complexes exist within the BMIMX-containing perovskite films, they are likely to exist throughout the bulk film.

For completeness, we investigate if the $\mathrm{BMIMBF}_{4}$ needs to be incorporated in the perovskite film, or if it can be preprocessed on the substrate prior to perovskite deposition. For the cells fabricated from this latter approach, which we refer to "with $\mathrm{BMIMBF}_{4}$ at the perovskite/NiO interface", we observe a small improvement in device efficiency, in comparison to the control cells, with higher $V_{O C}$ and FF (Extended Data Table1). The result is consistent with the enhanced efficiency for the cells based on $\mathrm{BMIMBF}_{4}$-containg perovskite films being related to the improved interfacial properties with an accumulation of BMIMBF 4 at the perovskite/NiO interface. However, we observe little positive effect upon the film 
stability with the $\mathrm{BMIMBF}_{4}$ at the perovskite/NiO interface (Extended Data Fig. 4c and 4d). Therefore, we conclude that the film stability improvement mainly originates from the presence of the BMIM in the perovskite film, with the $\mathrm{BF}_{4}$ being important so that the introduced IL does not negatively impact the film properties and the device performance of the ensuing solar cells. We assume that in the as-crystallised films, the large $[\mathrm{BMIM}]^{+}$ions are excluded from the perovskite crystals and hence accumulate at the surface and grain boundaries of the perovskite film. We postulate that the $[\mathrm{BMIM}]^{+}$cations will bind to surface sites which would have otherwise been susceptible to degradation via oxygen or moisture adsorption and subsequent reactions under light and heat ${ }^{27}$, and hence suppress the degradation of the perovskite active layer. However, as in the case for films processed with BMIMX, we speculate that the readily formed large band-gap complexes of $\mathrm{PbI}_{2}$ :BMIMX disrupt the perovskite lattice or introduce surface strain, and hence introduce electronic defects in the active layer, inhibiting the photovoltaic performance of the resulting devices ${ }^{20}$.

Having demonstrated the improved stability of the $\mathrm{BMIMBF}_{4}$-containing perovskite films, we now proceed to investigate the stability of complete PV cells under combined heat and light stressing. We first test the stability performance of non-encapsulated devices under full-spectrum sunlight at $60-65^{\circ} \mathrm{C}$ (Fig. 4a). We notice similar light soaking during the $J-V$ measurements of the aged devices (Extended Data Fig. 5a) and present the final peak $J-V$ determined PCE for non-encapsulated cells as a function of aging time in Fig. 4a. We observe no degradation of both devices during the first $20 \mathrm{~h}$. In contrast to our previous best-reported stability $^{6}$, and that of others studying n-i-p perovskite solar cells ${ }^{5}$, here we do not observe an early time light induced degradation or "burn-in". This is already a key step-forward, and we assign this primarily to the use of the $\mathrm{p}$-i-n device structure comprised of $\mathrm{NiO}$ hole-conductor and chromium $(\mathrm{Cr}) /$ chromium oxide $\left(\mathrm{Cr}_{2} \mathrm{O}_{3}\right)$ interlayer ${ }^{22,28}$. However, for the control device, the PCE quickly decreases to around zero after a further $\sim 80 \mathrm{~h}$ of aging. In contrast, the $\mathrm{BMIMBF}_{4}$-containing device retains $\sim 86 \%$ of its initial performance after $100 \mathrm{~h}$ of aging in air. The control device discolours in the regions beyond the electrode protected area, while the $\mathrm{BMIMBF}_{4}$-containing device shows no visible discolouration (Fig. 4a, insets), consistent 
with the enhanced device stability originating from the improved stability of $\mathrm{BMIMBF}_{4}$-containing perovskite active layer.

We encapsulated a series of cells and proceeded to probe the long-term stability of our devices. We measure improvement in the device performance and in some cases an obvious decrease of hysteresis in the $J-V$ curves after the device encapsulation (Extended Data Fig. 5b and 5c). In Extended Data Fig. 5d, we present a stability comparison between the devices with $\mathrm{BMIMBF}_{4}$ in the perovskite film and that with $\mathrm{BMIMBF}_{4}$ processed at the perovskite/ $\mathrm{NiO}$ interface, under full-spectrum sunlight at $60-65^{\circ} \mathrm{C}$. We observe no obvious degradation of the encapsulated devices under this aging condition. For the devices based on $\mathrm{BMIMBF}_{4}$-containing perovskite film, we measure an increase in both the $J-V$ derived efficiency and the SPO, together with a "healing" of the $J-V$ hysteresis after $150 \mathrm{~h}$ aging (Extended Data Fig. 5e and 5f).

We then allowed the chamber temperature to rise to between 70 to $75^{\circ} \mathrm{C}$ and proceeded to evaluate the device stability performance under increased elevated temperature. We show the device parameter evolution in Fig. 4b, 4c and Extended Data Fig. 6a-c. We measure the same degradation trend of the devices with the observed film stability, showing very little degradation in $J-V$ determined efficiency for the cells based on $\mathrm{BMIMBF}_{4}$-containing perovskite film, and a faster degradation of the control devices. The cells with $\mathrm{BMIMBF}_{4}$ at the perovskite/ $\mathrm{NiO}$ interface also degrade at a similar rate to the control cells under this higher temperature aging. Therefore, it appears essential that the $\mathrm{BMIMBF}_{4}$ is within the perovskite absorber in order to enhance the stability. However, we note that we observe increased hysteresis and in some instances the emergence of overshoot in the $J-V$ curves for the set of devices based on $\mathrm{BMIMBF}_{4}$-containing perovskite films during the $70-75{ }^{\circ} \mathrm{C}$ light stressing (Extended Data Fig. 6d). The SPO values exhibit a faster degradation than the $J-V$ determined efficiency, and we observe $\sim 20 \%$ decrease of the initial performance after the $1072 \mathrm{~h}$ of aging for cells based on $\mathrm{BMIMBF}_{4}$-containing perovskite films (Fig. 4c). In comparison, for the control cells and that with $\mathrm{BMIMBF}_{4}$ at the perovskite/NiO interface, we observe $\sim 35-40 \%$ drop in the SPO over the same aging period. 
In Fig. 4d we show the longer-term stability results aged under full-spectrum sunlight at the elevated temperature $\left(70-75^{\circ} \mathrm{C}\right)$ for the most stable cell with $\mathrm{BMIMBF}_{4}$ in the perovskite film. We observe a slow increase in the $J-V$ derived efficiency at the beginning of the aging. However, we also measure a small early time "burn-in" of the SPO during the first $\sim 100 \mathrm{~h}$, coincidental with enhanced $J-V$ hysteresis under the high-temperature aging condition, and proceed to measure a relatively slow drop in the SPO during the extended aging test. We show the $J-V$ and the measured SPO curves at different aging times in Extended Data Fig. 7a-7f, which clearly show the device performance evolution, including the increased device hysteresis in the $J-V$ curves, during the long-term aging test. Remarkably, the most stable device based on $\mathrm{BMIMBF}_{4}$-containing perovskite film exhibits only $\sim 5 \%$ degradation in the $J-V$ derived efficiency, and $\sim 15 \%$ degradation in the SPO over the entire $1885 \mathrm{~h}$ aging test.

Via fitting the degradation data of the best-performing device based on $\mathrm{BMIMBF}_{4}$-containing perovskite film using the illustrated methods in Extended Data Fig. 8, we estimate a time to $80 \%$ of the peak PCE $\left(T_{80}\right)$ of $\sim 5,200 \mathrm{~h}$, and the $T_{80}$ of the post "burn-in" SPO to be $\sim 4,100 \mathrm{~h}$. The $T_{80}$ of our $J-V$ determined PCE and SPO are 1.3 and 2.4 times as long respectively, as our previous best-reported stability for n-i-p solar cells ${ }^{28}$, which were aged at a lower temperature of 50 to $60{ }^{\circ} \mathrm{C}$ and exhibited a severe early time "burn-in", where over $20 \%$ of the initial efficiency was lost within the first few hundred hours. We would expect that an additional degradation acceleration factor due to a temperature increase is in a region of 4 -fold (2-fold per $10{ }^{\circ} \mathrm{C}$ increase in temperature $)^{29}$. We therefore estimate that the cells we present here are in the region of five to ten times more stable than our previous most-stable devices.

In order to put our results into broader context, we tabulate long-term stability performance of perovskite solar cells from literature in Extended Data Table 2, specifying the device structures, the aging conditions, the degradation factors and the estimated $T_{80}$. In comparison with the longest $T_{80}$ measured under combined light and heat stressing ${ }^{10}$, our cells here are stressed at $\sim 10-15{ }^{\circ} \mathrm{C}$ higher temperature along with UV light and deliver a comparable $T_{80}$ lifetime, indicating that our cells are likely to be at least twice as stable as the 
most stable cells reported so far in the literature. We note, that all the results we present in Extended Data Table 2 are measured under slightly different conditions (light source, atmosphere, electric bias conditions, temperature, etc.). Ultimately standardized measurement conditions, with which to fairly compare between experimental results in different labs, would greatly benefit the community ${ }^{30}$.

To demonstrate the applicability of our strategy on improving the device operational stability to different perovskite absorber materials, we undertook a similar aging test with the "unstable" perovskite, $\mathrm{MAPbI}_{3}$, in the same p-i-n device structure (Extended Data Fig. 9a-h). For our cells based on $\mathrm{BMIMBF}_{4}$-containing $\mathrm{MAPbI}_{3}$ aging at $\sim 60$ to $65{ }^{\circ} \mathrm{C}$, we observe a similar improvement in the device performance during the first $100 \mathrm{~h}$, while the control cells exhibit a slightly drop in performance. We then set the temperature of the aging box to $\sim 70$ to $75{ }^{\circ} \mathrm{C}$ for a short period to evaluate the degradation behavior of the devices under higher temperature. We observe a fast decrease in both the device efficiency and SPO for all devices. We subsequently dropped the temperature back to 60 to $65{ }^{\circ} \mathrm{C}$ and proceeded with the aging. The control devices exhibit a faster degradation after the high-temperature aging and quickly decrease to $\sim 60 \%$ of the original device performance after $\sim 400 \mathrm{~h}$. In contrast, devices with $\mathrm{BMIMBF}_{4}$ in the $\mathrm{MAPbI}_{3}$ perovskite slowly recover to their initial efficiency prior to the high-temperature aging and show less than $10 \%$ degradation in both the $J-V$ derived efficiency and SPO after $\sim 400 \mathrm{~h}$ aging under full-spectrum light and heat stressing (Extended Data Fig. 9).

In summary, we have presented a simple, broadly applicable method which greatly enhances the long-term operational stability of perovskite solar cells. We expect that our approach represents another key milestone towards a stable perovskite PV technology, and is likely to be applicable to other optoelectronic applications employing metal halide perovskites.

\section{References}

1. Lee, M. M., Teuscher, J., Miyasaka, T., Murakami, T. N. \& Snaith, H. J. Efficient hybrid solar cells based on meso-superstructured organometal halide perovskites. 
Science 338, 643-647, (2012).

2. Burschka, J. et al. Sequential deposition as a route to high-performance perovskite-sensitized solar cells. Nature 499, 316-319, (2013).

3. Jeon, N. J. et al. Compositional engineering of perovskite materials for high-performance solar cells. Nature 517, 476, (2015).

4. Liu, M., Johnston, M. B. \& Snaith, H. J. Efficient planar heterojunction perovskite solar cells by vapour deposition. Nature 501, 395-398, (2013).

5. Saliba, M. et al. Cesium-containing triple cation perovskite solar cells: improved stability, reproducibility and high efficiency. Energy Environ.Sci. 9, 1989-1997, (2016).

6. Wang, Z. et al. Efficient ambient-air-stable solar cells with 2D-3D heterostructured butylammonium-caesium-formamidinium lead halide perovskites. Nat. Energy 2, 17135, (2017).

7. McMeekin, D. P. et al. A mixed-cation lead mixed-halide perovskite absorber for tandem solar cells. Science 351, 151-155, (2016).

8. Saliba, M. et al. Incorporation of rubidium cations into perovskite solar cells improves photovoltaic performance. Science 354, 206-209, (2016).

9. Tsai, H. et al. High-efficiency two-dimensional Ruddlesden-Popper perovskite solar cells. Nature 536, 312-316, (2016).

10. Arora, N. et al. Perovskite solar cells with $\mathrm{CuSCN}$ hole extraction layers yield stabilized efficiencies greater than 20\%. Science 358, 768-771, (2017).

11. Chen, W. et al. Efficient and stable large-area perovskite solar cells with inorganic charge extraction layers. Science 350, 944-948, (2015).

12. Hou, Y. et al. A generic interface to reduce the efficiency-stability-cost gap of perovskite solar cells. Science 358, 1192-1197, (2017).

13. Christians, J. A. et al. Tailored interfaces of unencapsulated perovskite solar cells for $>1,000$ hour operational stability. Nat. Energy 3, 68-74, (2018).

14. Bella, F. et al. Improving efficiency and stability of perovskite solar cells with photocurable fluoropolymers. Science 354, 203-206, (2016).

15. Cheacharoen, R. et al. Design and understanding of encapsulated perovskite solar cells to withstand temperature cycling. Energy Environ.Sci. 11, 144-150, (2018).

16. Divitini, G. et al. In situ observation of heat-induced degradation of perovskite solar cells. Nat. Energy 1, 15012, (2016).

17. Leijtens, T. et al. Mapping electric field-induced switchable poling and structural degradation in hybrid lead halide perovskite thin films. Adv. Energy Mater. 5, 1500962, (2015).

18. Domanski, K. et al. Migration of cations induces reversible performance losses over day/night cycling in perovskite solar cells. Energy Environ.Sci. 10, 604-613, (2017).

19. Yang, D. et al. Surface optimization to eliminate hysteresis for record efficiency planar perovskite solar cells. Energy Environ.Sci. 9, 3071-3078, (2016).

20. Zhang, Y. et al. A strategy to produce high efficiency, high stability perovskite solar cells using functionalized ionic liquid-dopants. Adv. Mater. 29, 1702157, (2017). 
21. Luo, D. et al. Enhanced photovoltage for inverted planar heterojunction perovskite solar cells. Science 360, 1442-1446, (2018).

22. Nie, W. et al. Critical Role of Interface and Crystallinity on the Performance and Photostability of Perovskite Solar Cell on Nickel Oxide. Adv. Mater. 30, 1703879, (2018).

23. Li, C. et al. Real-time observation of iodide ion migration in methylammonium lead halide perovskites. Small 13, 1701711, (2017).

24. Li, C., Guerrero, A., Huettner, S. \& Bisquert, J. Unravelling the role of vacancies in lead halide perovskite through electrical switching of photoluminescence. Nat. Commun. 9, 5113, (2018).

25. Bryant, D. et al. Light and oxygen induced degradation limits the operational stability of methylammonium lead triiodide perovskite solar cells. Energy Environ.Sci. 9, 1655-1660, (2016).

26. Aristidou, N. et al. Fast oxygen diffusion and iodide defects mediate oxygen-induced degradation of perovskite solar cells. Nat. Commun. 8, 15218, (2017).

27. Sun, Q. et al. Role of microstructure in oxygen induced photodegradation of methylammonium lead triiodide perovskite films. Adv. Energy Mater. 7, 1700977, (2017).

28. Kaltenbrunner, M. et al. Flexible high power-per-weight perovskite solar cells with chromium oxide-metal contacts for improved stability in air. Nat. Mater. 14, 1032-1039, (2015).

29. Ross, J., R. G. Crystalline-silicon reliability lessons for thin-film modules. Proc. 18th IEEE Photovoltaic Specialists Conf., 1114-1020, (1985).

30. Snaith, H. J. \& Hacke, P. Enabling reliability assessments of pre-commercial perovskite photovoltaics with lessons learned from industrial standards. Nat. Energy 3, 459-465, (2018).

\section{Supplementary Information}

This file contains the Supplementary Table (Table S1), which includes the detailed information of all chemicals used in this work.

Acknowledgements This work was part funded by EPSRC (grant Nos. EP/M015254/2 and EP/M024881/1), the ERC Starting Grant (717026), the Swedish Research Council VR (grant No. 330-2014-6433), the European Commission Marie Skłodowska-Curie action (grant No. INCA 600398), the Swedish Government Strategic Research Area in Materials Science on Functional Materials at Linköping University (Faculty Grant SFO-Mat-LiU No. 2009-00971), and from the European Union's Horizon 2020 research and innovation program under grant 
agreement No 763977 of the PerTPV project. S.B. is a VINNMER Fellow and Marie Curie Fellow. P.D. and Z.Y. acknowledge the support from the China Scholarship Council (CSC). C. L. and S. H gratefully acknowledge the financial support by the Bavarian State Ministry of Science, Research, and the Arts for the Collaborative Research Network "Solar Technologies go Hybrid" and the German Research Foundation (DFG). M.K. acknowledges the support from Swiss National Science Foundation, Grant No. cr23i2-162828. We thank H. Long, Z. Yan, C. Bao, N. Noel, B. Wenger, J. Ball and O. Inganäs for experimental assistance and useful discussions.

Author Contributions S.B., F.G. and H.J.S. conceived the idea of the project, designed the experiments, analysed the data and wrote the manuscript. S.B. performed the fabrication, optimization, and characterization of the films and solar cells. P.D. contributed to the film characterization and stability test of the devices. C.L. and S.H. performed the characterization of ion migration process. S.B., Z.W. and Z.Y. performed the XRD and SEM characterizations. M.K., F.F. and S.Bu. conducted the ToF-SIMS measurements and analysed the data. X. L. and M.F. carried out the UPS and XPS measurements and analysed the data. S.B., Z.W. and N.S. performed the optical measurements. J.T-W. W contributed to the optimization of the p-i-n device architecture. All authors commented to the final version of the manuscript. F.G. and H.J.S. supervised the project.

Author Information H.J.S. is a co-founder, Chief Scientific Officer, and a Director of Oxford PV Ltd. Oxford University has filed a patent related to the subject matter of this manuscript. Correspondence and requests for materials should be addressed to S.B. (sai.bai@liu.se), F.G. (eng.gao@liu.se) and H.J.S (henry.snaith@physics.ox.ac.uk)

Data availability The data that support the findings of this study are available from the corresponding author upon reasonable request. 
a
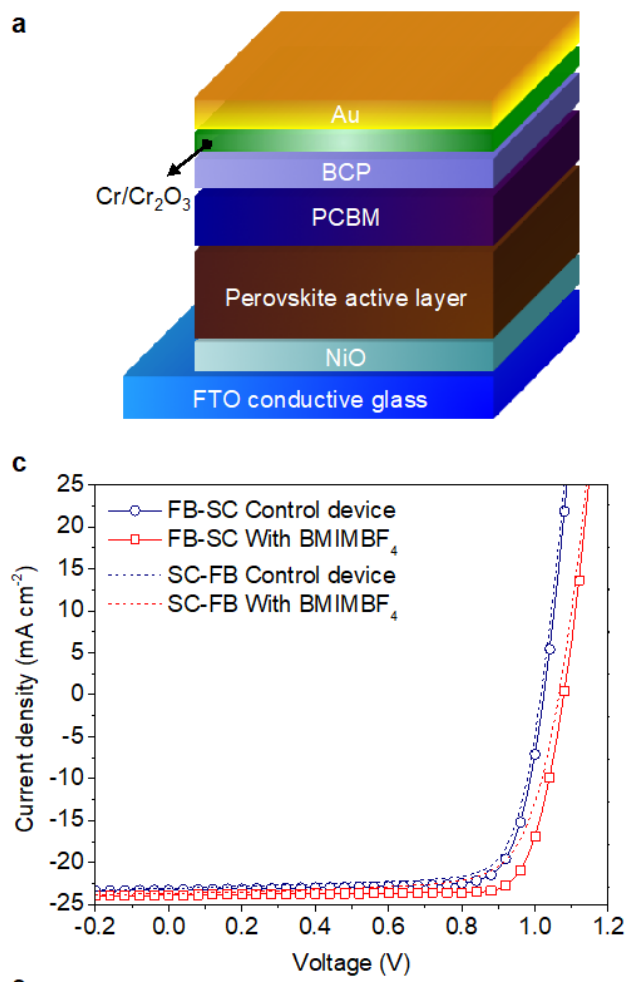

e

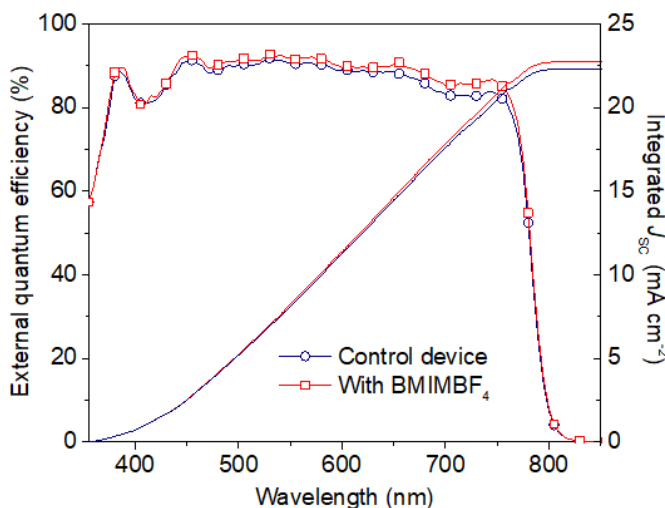

b

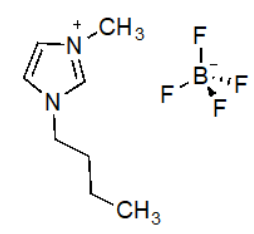

d

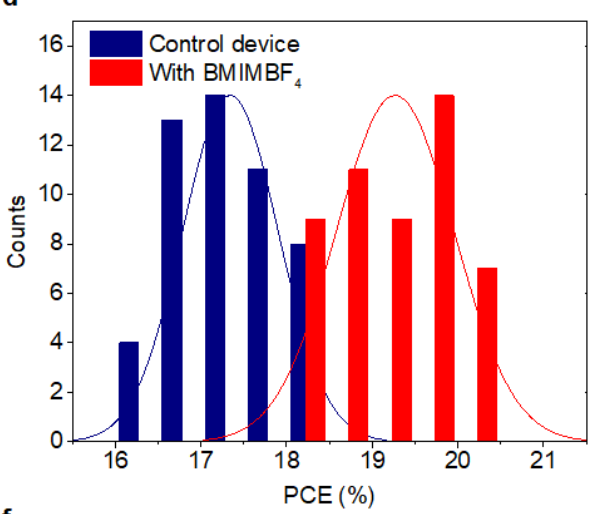

f

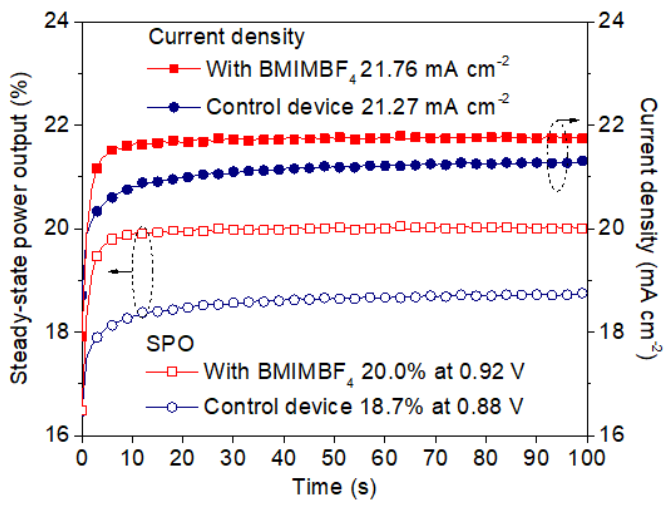

Figure 1 | Device architecture and characterization. a, Schematic device architecture of the planar heterojunction p-i-n perovskite solar cell. b, Chemical structure of the 1-butyl-3-methylimidazolium tetrafluoroborate $\left(\mathrm{BMIMBF}_{4}\right)$ ionic liquid. c-f, Characteristics of control (navy circle) and device with $\mathrm{BMIMBF}_{4}(0.3 \mathrm{~mol} \%)$ (red square). Current density-voltage $(J-V)$ curves measured from forward bias (FB) to short-circuit (SC) scan and back again (short dash line) under simulated AM1.5 sunlight. The light intensity for the measurement of the control and device with $\mathrm{BMIMBF}_{4}$ was 102 and $105 \mathrm{~mW} \mathrm{~cm} \mathrm{~cm}^{-2}$, respectively. (c). Histograms of the device efficiencies of 50 cells of each condition, control (navy) and device with optimal $\mathrm{BMIMBF}_{4}$ (red), fitted with a Gaussian distribution (solid line) (d). External quantum efficiency (EQE) spectra and the integrated photocurrent (solid 
line) over the AM1.5 solar spectrum of $100 \mathrm{~mW} \mathrm{~cm}^{-2}$ (e). The integrated $J_{\mathrm{SC}}$ values are 22.3 and $22.8 \mathrm{~mA} \mathrm{~cm}^{-2}$ for the control and device with $\mathrm{BMIMBF}_{4}$, respectively. Current density (solid circle and square) and the stabilised power output (SPO) (open circle and square) are determined at a fixed voltage near the maximum power point (MPP) from the $J-V$ curves for $100 \mathrm{~s}(\mathbf{f})$. 

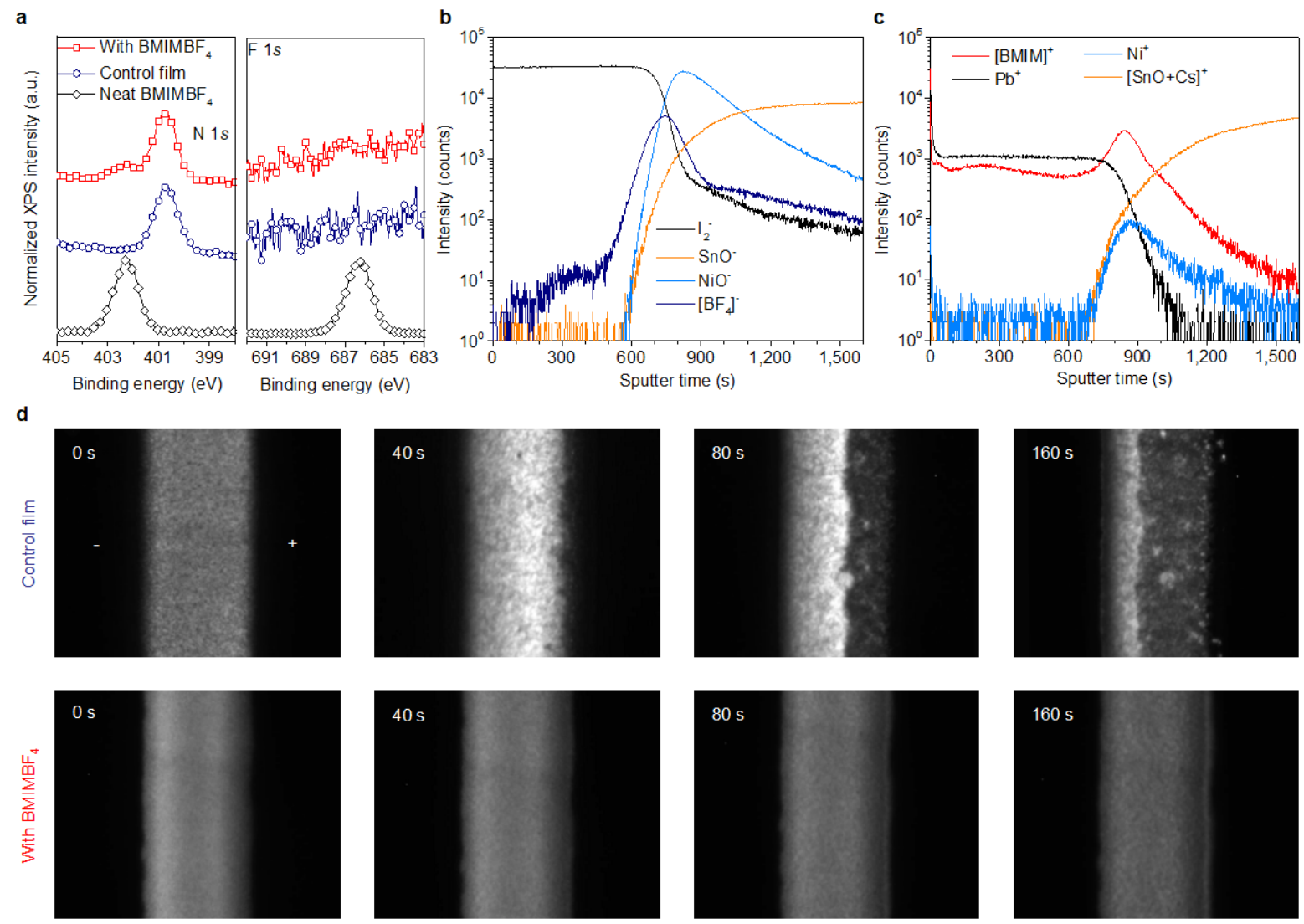

Figure 2 Composition distribution of $\mathrm{BMIMBF}_{4}$ in the perovskite active layer and its impact on the ion migration. a, N1s and F1s X-ray photoelectron spectroscopy (XPS) spectra of neat $\mathrm{BMIMBF}_{4}$ (black diamond), control film (navy circle) and film with $\mathrm{BMIMBF}_{4}(0.3 \mathrm{~mol} \%)$ (red square). b, c, Time-of-flight secondary ion mass spectrometry (ToF-SIMS) depth profiles of the $\mathrm{BMIMBF}_{4}$-containing perovskite film $(0.3 \mathrm{~mol} \%)$, measured in negative (b) and positive polarity (c). d, Photoluminescence (PL) images of the control film (top) and film with $\mathrm{BMIMBF}_{4}(0.3 \mathrm{~mol} \%)$ (bottom) under a constant applied bias $(10 \mathrm{~V})$. The bright areas represent PL emission of the perovskite films. 

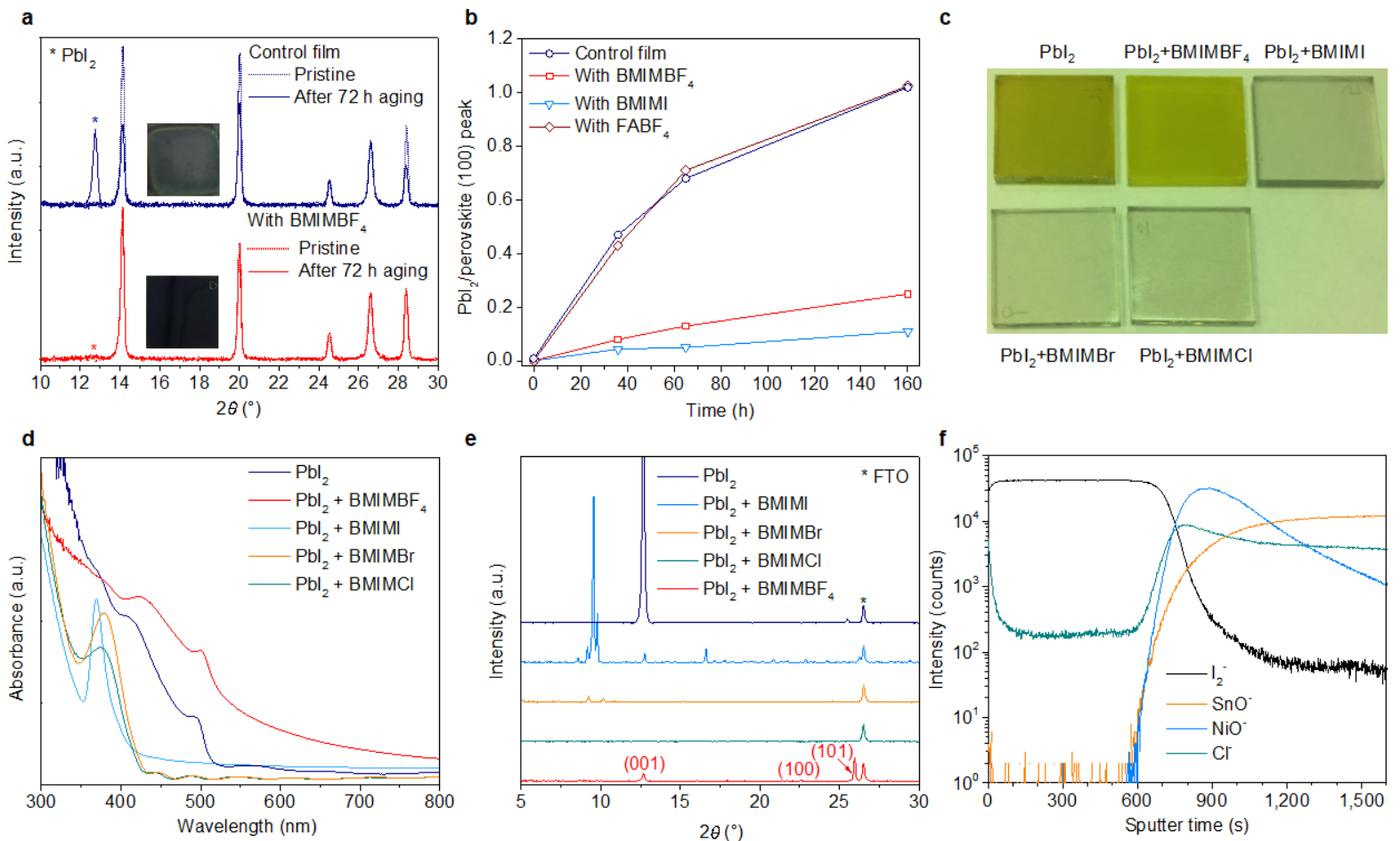

$\mathrm{PbI}_{2}+\mathrm{BMIMBr} \quad \mathrm{Pbl}_{2}+\mathrm{BMIMCl}$

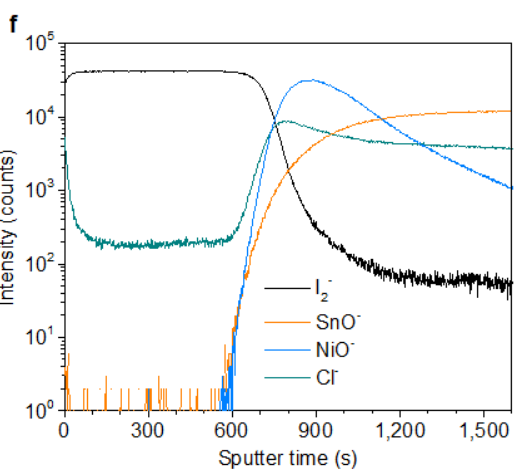

Figure 3 | Film stability and the interaction between PbI2 and BMIM-ILs. a, X-ray diffraction (XRD) patterns of the pristine (dash line) and aged (solid line) samples of control (navy) and film with $\mathrm{BMIMBF}_{4}(0.3 \mathrm{~mol} \%)$ (red) on $\mathrm{NiO} / \mathrm{FTO}$ substrates. Insets show images of the corresponding aged samples after $72 \mathrm{~h}$ light-soaking at $60-65^{\circ} \mathrm{C}$. b, Evolution of the ratio between $\mathrm{PbI}_{2}$ and perovskite (100) peak intensity in the XRD patterns of control and films with different ionic additives during the light aging at $70-75{ }^{\circ} \mathrm{C}$. c-e, Characterizations of thin films deposited from neat $\mathrm{PbI}_{2}$ solution and those composed of $\mathrm{PbI}_{2}$ and BMIM-ILs (1:1, molar ratio) on NiO/FTO substrates. Photographs (c), ultraviolet-visible (UV-Vis) absorption spectra (d) and XRD patterns (e). The $\mathrm{PbI}_{2}: \mathrm{BMIMBF}_{4}$ film retains the colour of $\mathrm{PbI}_{2}$ and exhibit a polycrystalline $\mathrm{PbI}_{2}$ feature. f, ToF-SIMS depth profiles measured in negative polarity of the BMIMCl-containing perovskite film $(0.3 \mathrm{~mol} \%)$ on $\mathrm{NiO} / \mathrm{FTO}$ substrate. 

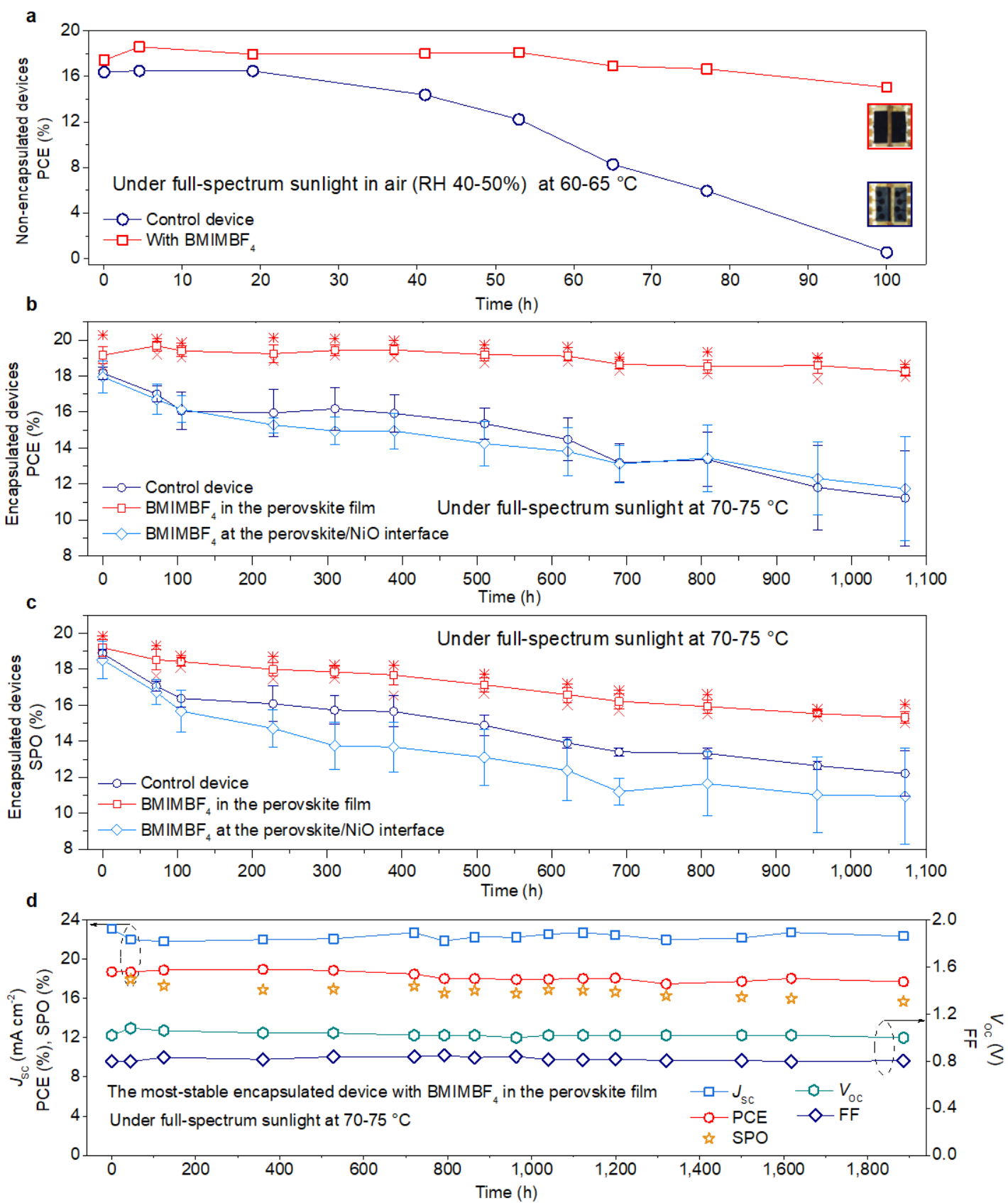

Figure 4 | Device stability under combined full-spectrum sunlight and heat stressing. a,

Average device efficiencies of non-encapsulated control (navy circle) and devices with $\mathrm{BMIMBF}_{4}(0.3 \mathrm{~mol} \%)$ (red square) under full-spectrum sunlight at $60-65{ }^{\circ} \mathrm{C}$ in air. Insets show pictures of the corresponding perovskite solar cells after $100 \mathrm{~h}$ aging. b, c, Device stability performance of the solar cells under full-spectrum sunlight with the temperature of the aging box at $70-75^{\circ} \mathrm{C}$. PCE (b) and SPO (c) with standard error are calculated from 10 cells (top 8 cells for the SPO) for devices with $\mathrm{BMIMBF}_{4}$ in the perovskite film and 7 cells (top 4 cells for the SPO) for the other two sets of devices. The top and bottom star represent 
the maximum and minimum values, respectively. $\mathbf{d}$, Long-term device stability performance of the most stable device based on $\mathrm{BMIMBF}_{4}$-containing $(0.3 \mathrm{~mol} \%)$ perovskite film under full-spectrum sunlight and heat stressing at $70-75^{\circ} \mathrm{C}$. The device parameters are calculated from the peak FB-SC scanned $J-V$ curves of the most stable device.

\section{METHODS}

Materials. Detailed information of all chemicals used in this work is listed in the Supplementary Information (Table S1).

Substrates preparation. FTO-coated glass (Pilkington TEC $7,7 \Omega / \square$ sheet resistivity) was etched with zinc powder and $2 \mathrm{M}$ hydrochloric acid $(\mathrm{HCl})$ to desired patterns. The substrates were cleaned with $2 \%$ solution of Hellmanex cuvette cleaning detergent, then subsequently washed with deionized water, and ethanol, and dried with dry nitrogen. The substrates were treated with UV-Ozone for $10 \mathrm{~min}$ before use. The Poly-TPD coated substrates were fabricated following the reported recipe ${ }^{31}$. The $\mathrm{NiO}$ precursor $(0.1 \mathrm{M})$ was prepared by dissolving nickel acetylacetonate $\left(\mathrm{Ni}(\mathrm{acac})_{2}\right)$ in anhydrous ethanol, and $\mathrm{HCl}(1 \% \mathrm{v} / \mathrm{v})$ was used as the stabilizer. The precursor solution was stirred overnight at room temperature, filtered $(0.45 \mu \mathrm{m}$, PTFE) and then spin-coated on cleaned FTO substrates at 4000 r.p.m for 40s. The films were dried at $180{ }^{\circ} \mathrm{C}$ for $10 \mathrm{~min}$ and then sintered at $400{ }^{\circ} \mathrm{C}$ in air for $45 \mathrm{~min}$ to obtain the compact layer of NiO. For the $\mathrm{BMIMBF}_{4}$ treated substrates, a $3 \mathrm{mg} / \mathrm{ml}$ $\mathrm{BMIMBF}_{4}$ solution in ethanol was spin-coated on the $\mathrm{NiO}$ substrates at 6000 r.p.m, following annealing at $100{ }^{\circ} \mathrm{C}$ for $10 \mathrm{~min}$ in the glove-box. The relative humidity during the spin-coating and the thermal annealing of $\mathrm{NiO}$ films ranged from $40-50 \%$ in our cleanroom.

Preparation of perovskite precursor solutions. All chemicals used for the perovskite precursor solutions are listed in the Supplementary Information (Table S1). We prepared the $\left(\mathrm{FA}_{0.83} \mathrm{MA}_{0.17}\right)_{0.95} \mathrm{Cs}_{0.05} \mathrm{~Pb}\left(\mathrm{I}_{0.9} \mathrm{Br}_{0.1}\right)_{3}$ triple-cation perovskite precursor solution $(1.3 \mathrm{M})$ by dissolving formamidinium iodide (FAI, $176.6 \mathrm{mg}$ ) and methylammonium iodide (MAI, 33.1 
mg), CsI, (16.9 mg), $\mathrm{PbI}_{2}(509.4 \mathrm{mg})$ and $\mathrm{PbBr}_{2}(71.6 \mathrm{mg})$ in $1 \mathrm{ml}$ mixed anhydrous solvent of $\quad N, N$-dimethylformamide (DMF), dimethyl sulfoxide (DMSO) and $N$-methyl-2-pyrrolidinone (NMP). The ratio of the solvents was fixed at 4/0.9/0.1 in volume (DMF/DMSO/NMP). In parallel, we prepared the ionic liquids containing perovskite precursor solution by dissolving the same components in the mixed solvent that contains different ionic liquids (1.2 mol\%). The perovskite precursor solutions were stirred overnight in the glove-box and filtered $(0.45 \mu \mathrm{m}, \mathrm{PTFE})$ before the spin-coating. The IL-containing precursor solutions with desired concentrations were prepared by mixing the precursor without and with IL $(1.2 \mathrm{~mol} \%)$ at different ratio. The precursor solutions for $\mathrm{MAPbI}_{3}$ perovskite $(1.4 \mathrm{M})$ were prepared by dissolving $\mathrm{PbI}_{2}$ and $\mathrm{MAI}$ with a molar ratio of $1: 1$ in anhydrous DMF/DMSO (4:1, volume ratio) without and with $\mathrm{BMIMBF}_{4}(0.3 \mathrm{~mol} \%)$. The perovskite precursor solutions were stirred overnight in the glove-box and filtered $(0.45 \mu \mathrm{m}$, PTFE) before use.

Device Fabrication. The triple-cation perovskite films were deposited in the glove-box using a solvent quenching method ${ }^{32}$ with anisole as the anti-solvent. In detail, $100 \mu 1$ perovskite precursor solution was dropped on the $\mathrm{NiO}$ coated FTO substrates $(2.8 \times 2.8 \mathrm{~cm})$ and spin-coated at 1300 r.p.m for $5 \mathrm{~s}(5 \mathrm{~s}$ ramp) and 5000 r.p.m for $30 \mathrm{~s}$ (5 s ramp). $250 \mu \mathrm{l}$ anhydrous anisole was quickly dropped on the substrates $5 \mathrm{~s}$ before the end of the program. The samples were immediately put on a pre-heated hot plate and annealed at $100{ }^{\circ} \mathrm{C}$ for 30 min. For $\mathrm{MAPbI}_{3}$ films, the precursor solution was spin-coated at 4000 r.p.m for $30 \mathrm{~s}$ in a dry-box with a controlled humidity of $\sim 20 \%{ }^{33}$. $250 \mu$ lanhydrous anisole was dropped on the substrates $10 \mathrm{~s}$ before the end of the program. The films were annealed at $80{ }^{\circ} \mathrm{C}$ for $5 \mathrm{~min}$. PCBM solution with a concentration of $20 \mathrm{mg} / \mathrm{ml}$ in chlorobenzene (CB)/1,2-dichlorobenzene (ODCB) $(3 / 1, v / v)$ was spin-coated on top of the perovskite films at a speed of 1800 r.p.m for $30 \mathrm{~s}$. The samples were then annealed at $100{ }^{\circ} \mathrm{C}$ for $10 \mathrm{~min}$. After cooling down to room temperature, we dynamically spin-coated bathocuproine (BCP) solution $(0.5 \mathrm{mg} / \mathrm{ml}$ in isopropanol) on top of the PCBM at a speed of 4000 r.p.m for $20 \mathrm{~s}$. We 
then took out the samples from the glove-box and finished the devices by thermally evaporating $\mathrm{Cr}(3.5 \mathrm{~nm})$ and $\mathrm{Au}$ electrode $(100 \mathrm{~nm})$ under a vacuum of $6 \times 10^{-6}$ torr with a thermal evaporator in ambient.

Solar cell characterization. The current density-voltage $(J-V)$ curves were measured in air with a Keithley 2400 source meter under AM1.5 sunlight generated using an ABET Class AAB sun 2000 simulator. The mismatch factor for the test cell, light source and National Renewable Energy Laboratories (NREL) calibrated KG5 filtered silicon reference cell was estimated and applied in order to correctly estimate the equivalent AM1.5 irradiance level. Prior to measurement of each set of devices, the intensity of the solar simulator was automatically measured using a KG5 reference cell, and this recorded intensity (which typically varied from 99 to $105 \mathrm{~mW} \mathrm{~cm}^{-2}$ ), was used to calculate the precise power conversion efficiency, where power conversion efficiency is (electrical power out $\div$ solar light power in) $\times 100 \%$. All devices were masked with a $0.0919 \mathrm{~cm}^{-2}$ metal aperture to define the active area and to eliminate edge effects. The $J-V$ curves were measured at a scan rate of $200 \mathrm{mV} \mathrm{s}^{-1}$ (delay time of $100 \mathrm{~ms}$ ) from 1.2 to $-0.2 \mathrm{~V}$ and then back again (from -0.2 to 1.2 $\mathrm{V})$. A stabilization time of $2 \mathrm{~s}$ at forward bias of $1.2 \mathrm{~V}$ under illumination was done prior to scanning. We measure the cells for multiple times until a peak performance was achieved. This typically took between 2 to $5 J-V$ scans in $\sim 1$ to 2 minutes per cell. External quantum efficiency measurements were performed using custom-built Fourier transform photocurrent spectroscopy based on the Bruker Vertex 80v Fourier transform spectrometer. A Newport AAA sun simulator was used as the light source and the light intensity was calibrated with a Newport-calibrated reference silicon photodiode.

Film characterization. The morphologies of the perovskite films on $\mathrm{NiO}$ coated FTO substrates were characterized using a SEM (Hitachi S-4300) at an accelerating voltage of 3-5 $\mathrm{kV}$. The diffraction patterns were measured from samples of perovskite films on $\mathrm{NiO}$ coated FTO substrates using a Panalytical X'PERT Pro X-ray diffractometer. UV-Vis absorption 
spectra were measured using a Varian Carry 300 Bio (Agilent Technologies). Steady-state and time-resolved PL spectra were acquired using a Fluorescence lifetime spectrometer (FLuo Time 300, PicoQuant). The samples were excited using a $507 \mathrm{~nm}$ laser (LDH-P-C-510, PicoQuant) with pulse duration of $117 \mathrm{ps}$, fluence of $\sim 30 \mathrm{~nJ} \mathrm{~cm} \mathrm{~cm}^{-2}$ per pulse and a repetition rate of $1 \mathrm{MHz}$. The PL data was collected using a high-resolution monochromator and hybrid photomultiplier detector assembly (PMA Hybrid 40, PicoQuant GmbH). The samples were prepared on thin insulating amorphous $\mathrm{TiO}_{2}$-coated glass substrates to avoid the impact of morphology and structure change of perovskite films on the PL measurements ${ }^{34}$. Ultraviolet photoelectron spectroscopy (UPS) and X-ray photoelectron spectroscopy (XPS) measurements were carried out using a Scienta ESCA 200 spectrometer in ultrahigh vacuum with a base pressure of $1 \times 10^{-10}$ mbar. The measurement chamber is equipped with a monochromatic Al (K alpha) x-ray source providing photons with $1486.6 \mathrm{eV}$ for XPS and a standard He-discharge lamp with He I $21.22 \mathrm{eV}$ for UPS. The XPS experimental condition was set so that the full width at half maximum of the clean $\mathrm{Au} 4 f_{7 / 2}$ line (at the binding energy of $84.00 \mathrm{eV}$ ) was $0.65 \mathrm{eV}$. The total energy resolution UPS measurement is about $80 \mathrm{meV}$ as extracted from the width of the Fermi level (at the binding energy of $0.00 \mathrm{eV}$ ) of clean gold foil. All spectra were measured at a photoelectron takeoff angle of $0^{\circ}$ (normal emission). The work function of film was extracted from the edge of the secondary electron cutoff of the UPS spectra by applying a bias of $-3 \mathrm{~V}$ to the sample.

Time-of-flight secondary ion mass spectrometry (ToF-SIMS) measurements. The compositional depth profiling of perovskite films was obtained using a ToF-SIMS 5 system from ION-TOF operated in the spectral mode using a $25 \mathrm{keV} \mathrm{Bi}_{3}{ }^{+}$primary ion beam with an ion current of $0.7 \mathrm{pA}$. A mass resolving power of ca. $8000 \mathrm{~m} / \Delta \mathrm{m}$ was reached. For depth profiling a $500 \mathrm{eV} \mathrm{Cs}^{+}$sputter beam with a current of $28 \mathrm{nA}$ was used to remove material layer-by-layer in interlaced mode from a raster area of $300 \mu \mathrm{m} \times 300 \mu \mathrm{m}$. The mass-spectrometry was performed on an area of $100 \mu \mathrm{m} \times 100 \mu \mathrm{m}$ in the center of the sputter crater. A low-energy electron flood gun was used for charge compensation. In the positive 
polarity, the $[\mathrm{SnO}+\mathrm{Cs}]^{+}$secondary ion is the $\mathrm{SnO}$ fragment ionized through interaction with the sputter ion $\mathrm{Cs}^{+}$, which yields the highest signal-to-noise ratio positive secondary ion signal characteristic for the FTO substrate.

In-plane electronic device characterization. For the PL imaging experiments under electric field, perovskite films on glass samples were deposited with planar Au electrodes on top (channel width of $\sim 150 \mu \mathrm{m}$ ). The characterization method was performed following previous report based on a home-build PL imaging microscope $e^{23,24}$. Based on a commercial microscopy (Microscope Axio Imager.A2m), samples were illuminated by a LED illuminator using an excitation filter and dicroic mirror (HC 440 SP, AHF analysentechnik AG) allowing an excitation at $440 \mathrm{~nm}$. The excitation power could be controlled and was set to $\sim 34 \mathrm{~mW}$ $\mathrm{cm}^{-2}$ in the focus plane using an infinity-corrected objective $(10 \times / 0.25 \mathrm{HD}$, Zeiss). The PL light was filtered (HC-BS 484, AHF analysentechnik AG) to suppress residual excited light and directed to the microscope with the same objective lens. The PL signal was imaged with a CCD camera (Pco. Pixelfly, PCO AG) with the exposure time of $200 \mathrm{~ms}$. The perovskite films were placed in the focal plane of the objective lens. The PL changing process was recorded with a constant $10 \mathrm{~V}$ voltage being applied between the Au electrodes (Keithley 236 Source Measure Unit).

Film and device stability characterization. The complete perovskite solar cells were simply encapsulated with a cover glass (LT-Cover, Lumtec) and UV adhesive (LT-U001, Lumtec) in a nitrogen-filled glove-box. All the non-encapsulated perovskite films on $\mathrm{NiO} / \mathrm{FTO}$ substrates, encapsulated and non-encapsulated devices were aged using in an Atlas SUNTEST XLS+ (1,700 W air-colled Xenon lamp) light-soaking chamber under simulated full-spectrum AM1.5 sunlight with $76 \mathrm{~mW} \mathrm{~cm}$ cm $^{-2}$ irradiance. All devices were aged under open-circuit conditions, and were taken out from the chamber and tested at different time intervals under a separate solar simulator (AM1.5, 99-105 $\mathrm{mW} \mathrm{cm}^{-2}$ ) for $J-V$ characterizations. No additional ultraviolet filter was used during the whole aging process. During the aging test, temperature 
of the light aging chamber was initially set between $60-65^{\circ} \mathrm{C}$, and proceeding to $70-75^{\circ} \mathrm{C}$, as measured on a black temperature standard inserted in the aging box. When measuring the cells during aging, we remove the cells from the light aging chamber and allow them to cool to room temperature, which typically takes a few minutes. The relative humidity in the laboratory was monitored in a range of $40-60 \%$ during the entire aging test.

\section{Additional references}

31. Wang, J. T.-W. et al. Efficient perovskite solar cells by metal ion doping. Energy Environ.Sci. 9, 2892-2901, (2016).

32. Jeon, N. J. et al. Solvent engineering for high-performance inorganic-organic hybrid perovskite solar cells. Nat. Mater. 13, 897, (2014).

33. Bai, S. et al. Reproducible planar heterojunction solar cells based on one-step solution-processed methylammonium lead halide perovskites. Chemistry of Materials 29, 462-473, (2017).

34. Wang, Z. et al. Efficient and air-stable mixed-cation lead mixed-halide perovskite solar cells with n-doped organic electron extraction layers. Adv. Mater. 29, 1604186, (2017).

35. Mei, A. et al. A hole-conductor-free, fully printable mesoscopic perovskite solar cell with high stability. Science 345, 295-298, (2014).

36. Shin, S. S. et al. Colloidally prepared La-doped $\mathrm{BaSnO}_{3}$ electrodes for efficient, photostable perovskite solar cells. Science 356, 167-171, (2017).

37. Tan, H. et al. Efficient and stable solution-processed planar perovskite solar cells via contact passivation. Science 355, 722-726, (2017).

38. Bush, K. A. et al. 23.6\%-efficient monolithic perovskite/silicon tandem solar cells with improved stability. Nat. Energy 2, 17009, (2017). 
Extended Data table and legends

Extended Data table 1 | Summarized device parameters of the perovskite solar cells

\begin{tabular}{|c|c|c|c|c|c|c|}
\hline Devices & $\begin{array}{l}\text { Light intensity* } \\
\qquad\left(\mathrm{mW} \mathrm{cm}^{-2}\right)\end{array}$ & $\begin{array}{l}\text { Measured } J_{\mathrm{sc}} \\
\qquad\left(\mathrm{mA} \mathrm{cm}{ }^{-2}\right)\end{array}$ & $\begin{array}{c}\text { Measured } V_{o c} \\
\text { (V) }\end{array}$ & $\begin{array}{c}\text { Measured } \\
\text { FF }\end{array}$ & PCE (\%) & SPO (\%) \\
\hline \multicolumn{7}{|c|}{ Control devices } \\
\hline Average $^{\dagger}$ & $102 \pm 1$ & $22.5 \pm 0.6$ & $1.01 \pm 0.02$ & $0.77 \pm 0.02$ & $17.3 \pm 0.6$ & $17.6 \pm 0.6$ \\
\hline Champion & 102 & 23.2 & 1.02 & 0.79 & 18.5 & 18.7 \\
\hline \multicolumn{7}{|c|}{ Devices with $\mathrm{BMIMBF}_{4}$ at the perovskite/NiO interface } \\
\hline Average $^{\dagger}$ & $103 \pm 2$ & $22.7 \pm 0.8$ & $1.03 \pm 0.02$ & $0.79 \pm 0.02$ & $17.9 \pm 0.8$ & $17.9 \pm 0.8$ \\
\hline Champion & 105 & 23.6 & 1.06 & 0.81 & 19.3 & 19.5 \\
\hline \multicolumn{7}{|c|}{ Devices with $\mathrm{BMIMBF}_{4}$ in the perovskite film } \\
\hline Average $^{\dagger}$ & $104 \pm 1$ & $23.1 \pm 0.6$ & $1.07 \pm 0.02$ & $0.81 \pm 0.02$ & $19.3 \pm 0.7$ & $19.6 \pm 0.2$ \\
\hline Champion & 105 & 23.8 & 1.08 & 0.81 & 19.8 & 20.0 \\
\hline
\end{tabular}

${ }^{*}$ Light intensity of the solar simulator varied from 99 to $105 \mathrm{~mW} \mathrm{~cm}^{-2}$ for the measurements of the different batches of cells.

tThe average device parameters of $J_{S C}, V_{O C}, \mathrm{FF}$ and PCE with standard deviation are calculated based on 50 devices from over 5 different batches of each condition prior to aging. The average SPO with standard deviation is obtained based on the measured 20 high-performance cells of each condition. 
Extended data Table 2 | Comparison of our device performance with literature reported long-term operational stability of perovskite solar cells.

\begin{tabular}{|c|c|c|c|c|c|c|}
\hline Device Structure & Light source & Ageing condition & Degradation factor & $\begin{array}{c}\text { Initial } \\
\text { PCE (\%) }\end{array}$ & Estimated $T_{80}(\mathrm{hrs})$ & Reference \\
\hline \multicolumn{7}{|l|}{ Mesoporous structure } \\
\hline $\mathrm{FTO} / \mathrm{c}-\mathrm{TiO}_{2} / \mathrm{Li}$-doped meso- $\mathrm{TiO}_{2}$ & \multirow[t]{2}{*}{ White LED } & Nitrogen, MPP, & Light (without UV), & \multirow[t]{2}{*}{$\sim 17$} & $\sim 1,700$ & \multirow[t]{2}{*}{8} \\
\hline + perovskite/PTAA/Au & & $500 \mathrm{~h}$ & $85^{\circ} \mathrm{C}$ & & (Burn-in) & \\
\hline $\mathrm{FTO} / \mathrm{c}-\mathrm{TiO}_{2} / \mathrm{Li}$-doped meso $\mathrm{TiO}_{2}$ & \multirow[t]{4}{*}{ White LED } & Nitrogen, MPP, & Light (without UV), & $\sim 20$ & $\sim 5,700$ & 10 \\
\hline + perovskite/CuSCN/r-GO/Au & & $1,000 \mathrm{~h}$ & $60^{\circ} \mathrm{C}$ & & & \\
\hline 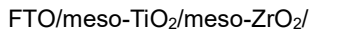 & & Ambient air, & Light (-), air & \multirow[t]{2}{*}{$\sim 11$} & \multirow[t]{2}{*}{-} & \multirow[t]{2}{*}{35} \\
\hline perovskite/carbon & & $1,008 \mathrm{~h}$ & & & & \\
\hline \multicolumn{7}{|l|}{ Planar n-i-p structure } \\
\hline FTO/BaSnO $3:$ La/perovskite/ & Metal-halide & Ambient air, sealed, & Light (with UV) & $\sim 14$ & - & 36 \\
\hline $\mathrm{NiO} / \mathrm{FTO}$ & lamp & open-circuit, $1,000 \mathrm{~h}$ & & & & \\
\hline FTO/SnO $/$ PCBM/perovskite/ & \multirow[t]{2}{*}{ Xenon lamp } & Ambient air, sealed, & Light (with UV) & \multirow[t]{2}{*}{$\sim 17$} & $\sim 3,900$ & \multirow[t]{2}{*}{6} \\
\hline Spiro-OMeTAD/Au & & open-circuit, $2,400 \mathrm{~h}$ & $50-60{ }^{\circ} \mathrm{C}$ & & (Burn-in) & \\
\hline ITO/TiO $2-\mathrm{Cl} /$ perovskite/ & Xenon lamp* & Nitrogen, MPP, $500 \mathrm{~h}$ & Light (without UV) & $\sim 20$ & $\sim 1,600$ & 37 \\
\hline \multicolumn{7}{|l|}{ Spiro-OMeTAD/Au } \\
\hline ITO/C $60-\mathrm{SAM} / \mathrm{SnO}_{x} / \mathrm{PCBM} /$ & \multirow[t]{3}{*}{ White LED } & Nitrogen, & Light (without UV) & $\sim 20$ & $\sim 1,600$ & 12 \\
\hline perovskite/polymer/Ta-WOx/Au & & open-circuit, $1,000 \mathrm{~h}$ & & & (Light-soaking) & \\
\hline \multirow{4}{*}{$\begin{array}{l}\mathrm{FTO} / \mathrm{SnO}_{2} / \text { perovskite/EH44/ } \\
\mathrm{MoO}_{x} / \mathrm{Al}\end{array}$} & & Ambient air, MPP, & Light (with UV), air, & $\sim 12$ & $\sim 2500$ & 13 \\
\hline & \multirow{3}{*}{$\begin{array}{l}\text { Sulphur } \\
\text { plasma lamp }\end{array}$} & $1,000 \mathrm{~h}$ & $\sim 30^{\circ} \mathrm{C}$ & & (Light-soaking) & \\
\hline & & Nitrogen, MPP, & Light (with UV), & $\sim 16$ & - & 13 \\
\hline & & $1,500 \mathrm{~h}$ & $\sim 30^{\circ} \mathrm{C}$ & & & \\
\hline \multicolumn{7}{|l|}{ Planar p-i-n structure: } \\
\hline FTO/LiMgNiO/perovskite/PCBM & \multirow[t]{2}{*}{ Xenon lamp* } & Ambient air, sealed, & Light (without UV), & \multirow[t]{2}{*}{$\sim 16$} & \multirow[t]{2}{*}{$\sim 2200$} & \multirow[t]{2}{*}{11} \\
\hline$/ \mathrm{Nb}-\mathrm{TiO}_{2} / \mathrm{Ag}$ & & MPP, $1,000 \mathrm{~h}$ & $45-50{ }^{\circ} \mathrm{C}$ & & & \\
\hline ITO/NiO/perovskite/PCBM/ & Sulphur & Ambient air ${ }^{\dagger}$, MPP, & Light (with UV), & $\sim 13$ & $\sim 2,000$ & 38 \\
\hline $\mathrm{SnO}_{2} / \mathrm{ZTO} / \mathrm{ITO} / \mathrm{LiF} / \mathrm{Ag}$ & plasma lamp & $1,000 \mathrm{~h}$ & $\sim 35^{\circ} \mathrm{C}$ & & (Light-soaking) & \\
\hline \multirow{3}{*}{$\begin{array}{l}\text { ITO/PEDOT:PSS/2D } \\
\text { perovskite/PCBM/AI }\end{array}$} & \multirow[t]{2}{*}{ Xenon lamp } & Ambient air, sealed, & \multirow[t]{2}{*}{ Light (with UV) } & \multirow[t]{2}{*}{-} & \multirow[t]{2}{*}{-} & \multirow[t]{2}{*}{9} \\
\hline & & open-circuit, $2,250 \mathrm{~h}$ & & & & \\
\hline & \multirow{4}{*}{ Xenon lamp } & & & $\sim 19$ & $\sim 5,200$ & \multirow{4}{*}{ This work } \\
\hline \multirow{3}{*}{$\begin{array}{l}\text { FTO/NiO/perovskite/ } \\
\text { PCBM/BCP/Cr}\left(\mathrm{Cr}_{2} \mathrm{O}_{3}\right) / \mathrm{Au}\end{array}$} & & Ambient air, sealed, & Light (with UV), & & (PCE, Light-soaking) & \\
\hline & & open-circuit, $1,885 \mathrm{~h}$ & $70-75^{\circ} \mathrm{C}$ & $\sim 18$ & $\sim 4,100$ & \\
\hline & & & & & (SPO, Burn-in) & \\
\hline
\end{tabular}

*420 nm cut-off UV-filter was used during the stability test.

†The sputtered ITO electrode acts as a protection layer in the solar cell. 


\section{Extended Data figures}
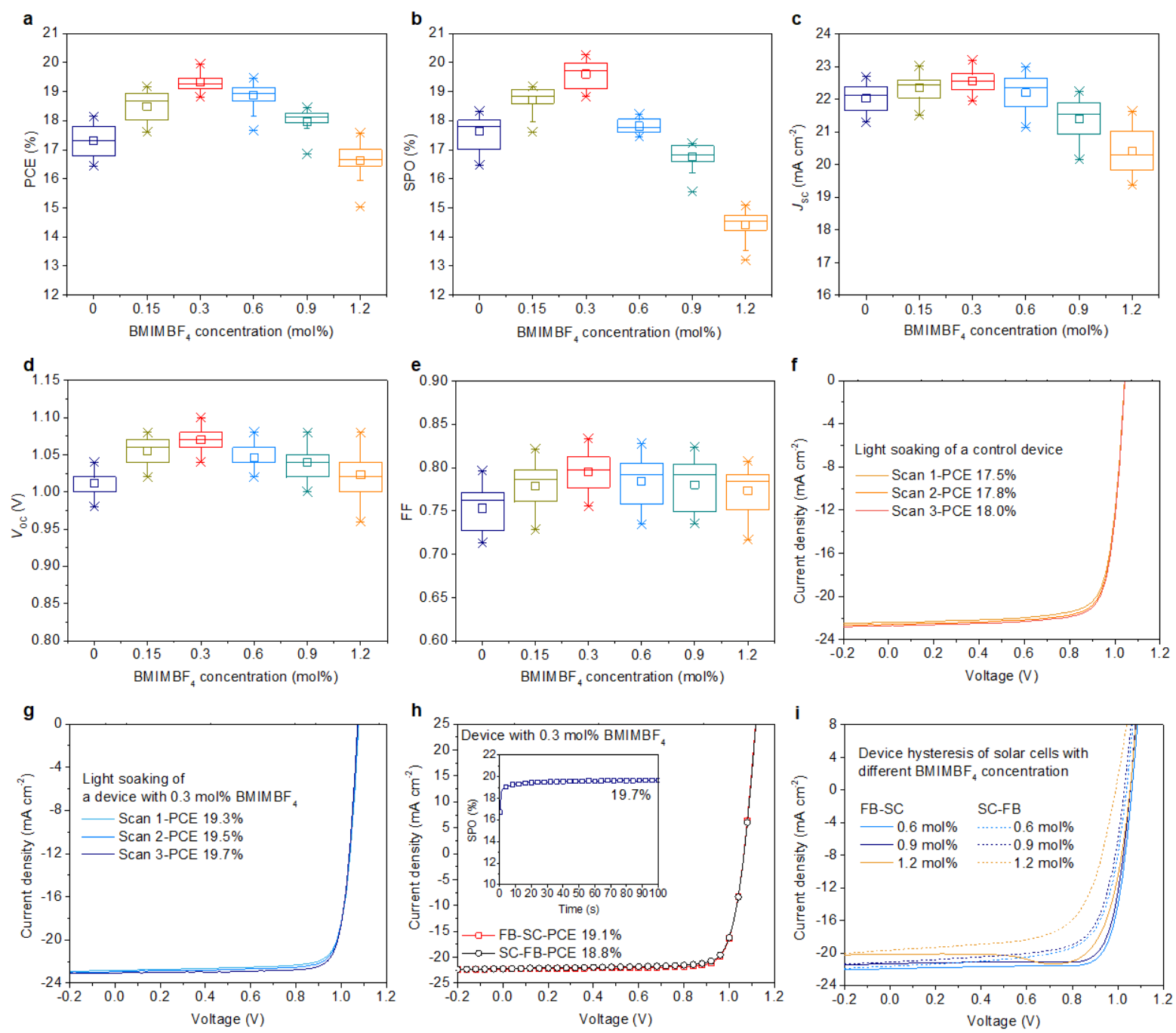

\section{Extended Data Figure $1 \mid$ Impact of $\mathrm{BMIMBF}_{4}$ concentration on the device performance.}

a-e, Statistics of device parameters of solar cells fabricated from perovskite precursors with the $\mathrm{BMIMBF}_{4}$ concentration ranging from 0 to $1.2 \mathrm{~mol} \%$ (with respect to $\mathrm{Pb}$ atom). The power conversion efficiency $(\mathrm{PCE})(\mathbf{a})$, short-circuit current $\left(J_{\mathrm{SC}}\right)(\mathbf{c})$, open-circuit voltage $\left(V_{\mathrm{OC}}\right)(\mathbf{d})$, and fill factor $(\mathrm{FF})(\mathbf{e})$ are determined from the forward bias (FB) to short-circuit (SC) current-voltage $(J-V)$ scan curves. The stabilised power output (SPO) (b) is determined at a fixed voltage near the maximum power point (MPP) from the $J$ - $V$ curves for $50 \mathrm{~s}$. The top and bottom star shows the maximum value and the minimum value, respectively; the open square shows the mean value and the box show the region containing $25-75 \%$ of the data, obtained from twenty cells for each condition. f, g, Light soaking during the $J-V$ curve measurements of the control (f) and device with $0.3 \mathrm{~mol}_{0} \mathrm{BMIMBF}_{4}(\mathbf{g}) \cdot \mathbf{h}, J-V$ curves of an 
optimized solar cell with 0.3 mol \% $\mathrm{BMIMBF}_{4}$ measured from $\mathrm{FB}$ to $\mathrm{SC}$ (red square) and back again (black circle) with a scan rate of $200 \mathrm{mV} \mathrm{s}^{-1}$. Inset shows the SPO curve of the device. i, Hysteresis in the $J-V$ curves of devices with increasingly higher concentration of $\mathrm{BMIMBF}_{4}$ in the perovskite layer. 

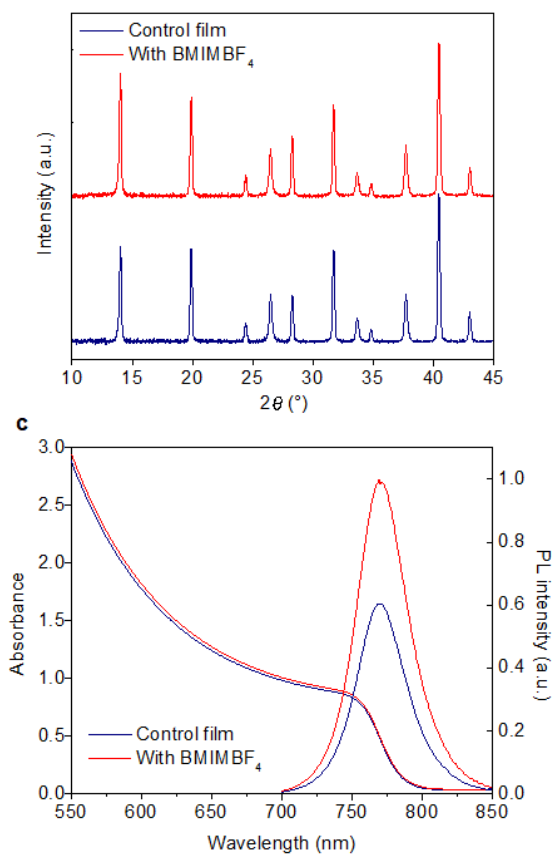

b
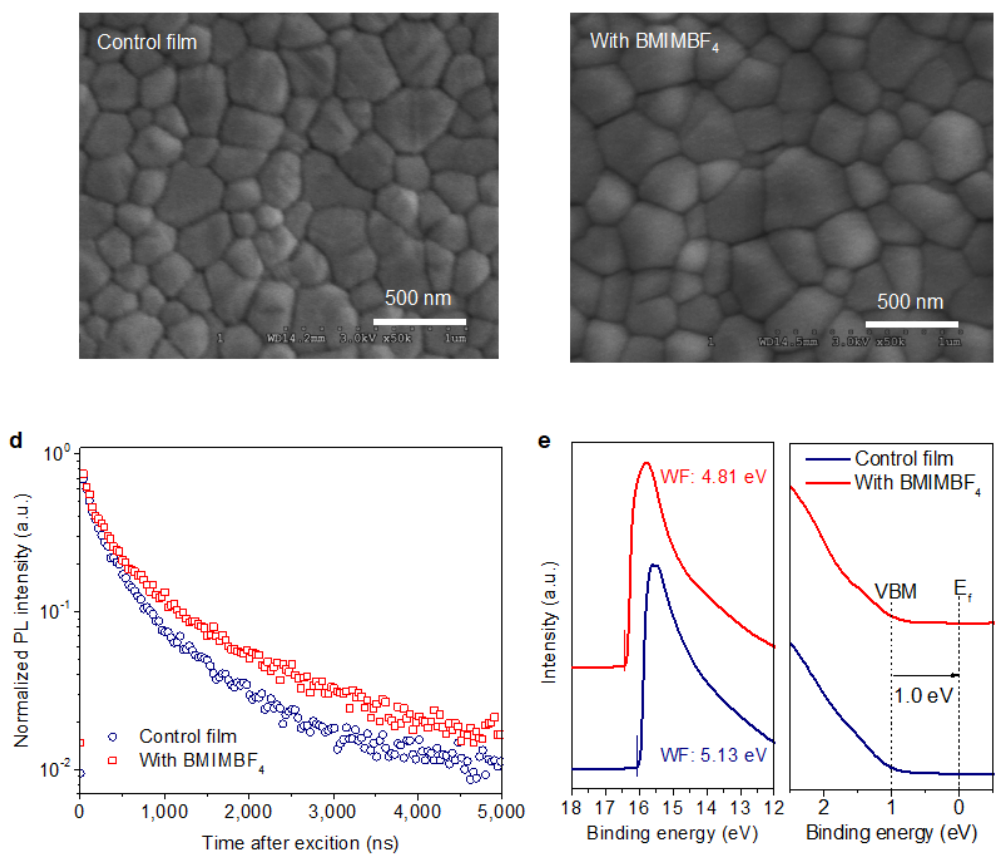

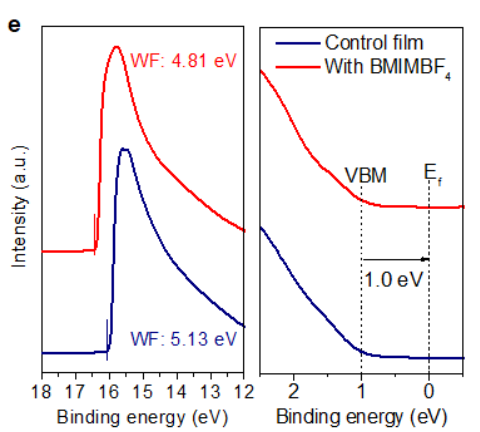

Extended Data Figure 2 Perovskite film characterizations. a-e, Characteristics of the control (navy) and film with $\mathrm{BMIMBF}_{4}(0.3 \mathrm{~mol} \%$ ) (red). X-ray diffraction (XRD) patterns (a). Top-view SEM images (b). Ultraviolet-visible (UV-Vis) absorption and steady-state photoluminescence (PL) spectra (c). Time-resolved PL decay curves (d). Photoemission cut-off energy and valence band region of the ultraviolet photoelectron spectroscopy (UPS) spectra (e). WF: work-function, VBM: valance band maximum, Ef: Fermi level. 

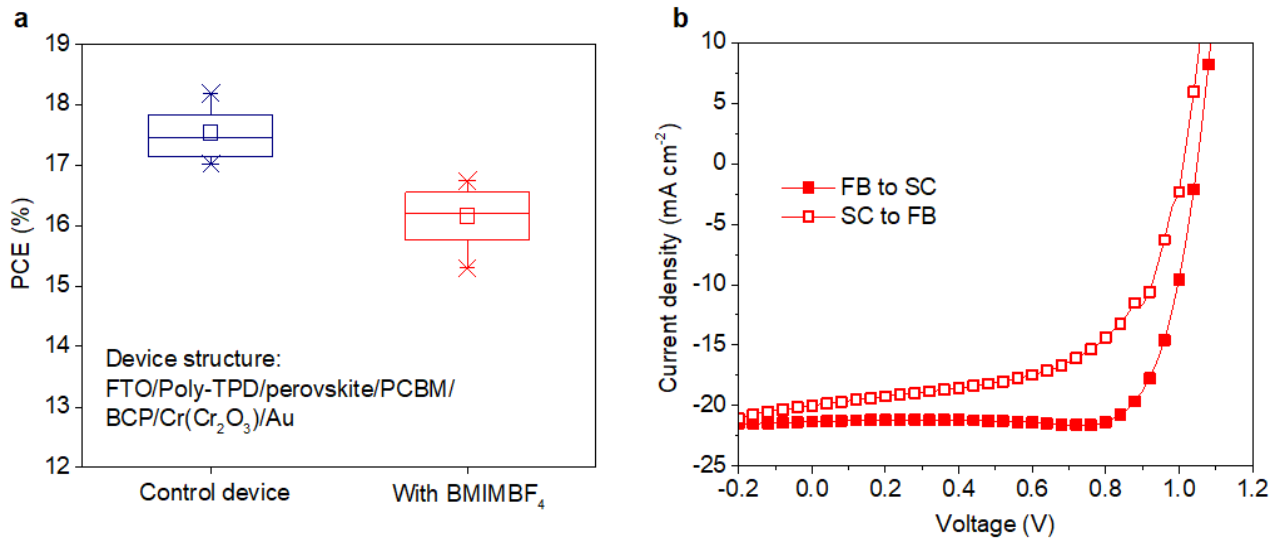

Extended Data Figure 3 | Perovskite solar cells on poly-TPD hole-conductor. a, Statistics of PCEs of perovskite solar cells fabricated from precursors without (navy) and with $0.3 \mathrm{~mol} \%$ $\mathrm{BMIMBF}_{4}(\mathrm{red})$ on poly-TPD coated FTO substrates. The PCEs are determined from FB-SC $J-V$ scan curves of 13 cells for each condition. The bottom and top star represents the minimum and maximum value, respectively; the open square represents the mean value and the box show the region containing $25-75 \%$ of the data. $\mathbf{b}, J-V$ curves of the device fabricated on poly-TPD/FTO with $0.3 \mathrm{~mol}_{0} \mathrm{BMIMBF}_{4}$ in the perovskite film, measured from FB to SC (solid square) and back again (open square) with a scan rate of $200 \mathrm{mV} \mathrm{s}^{-1}$. 


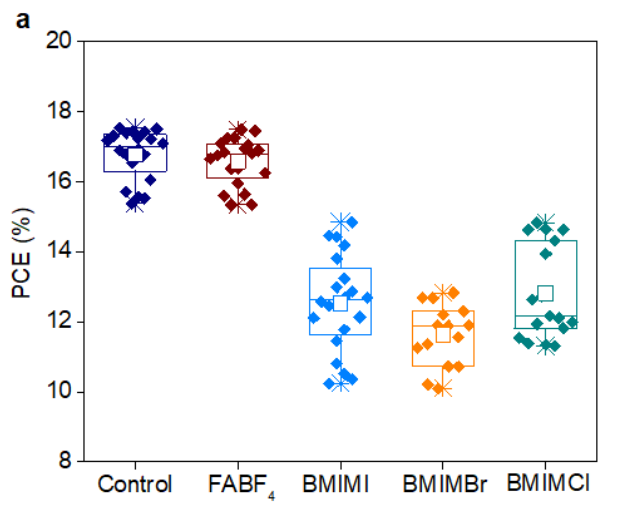

b
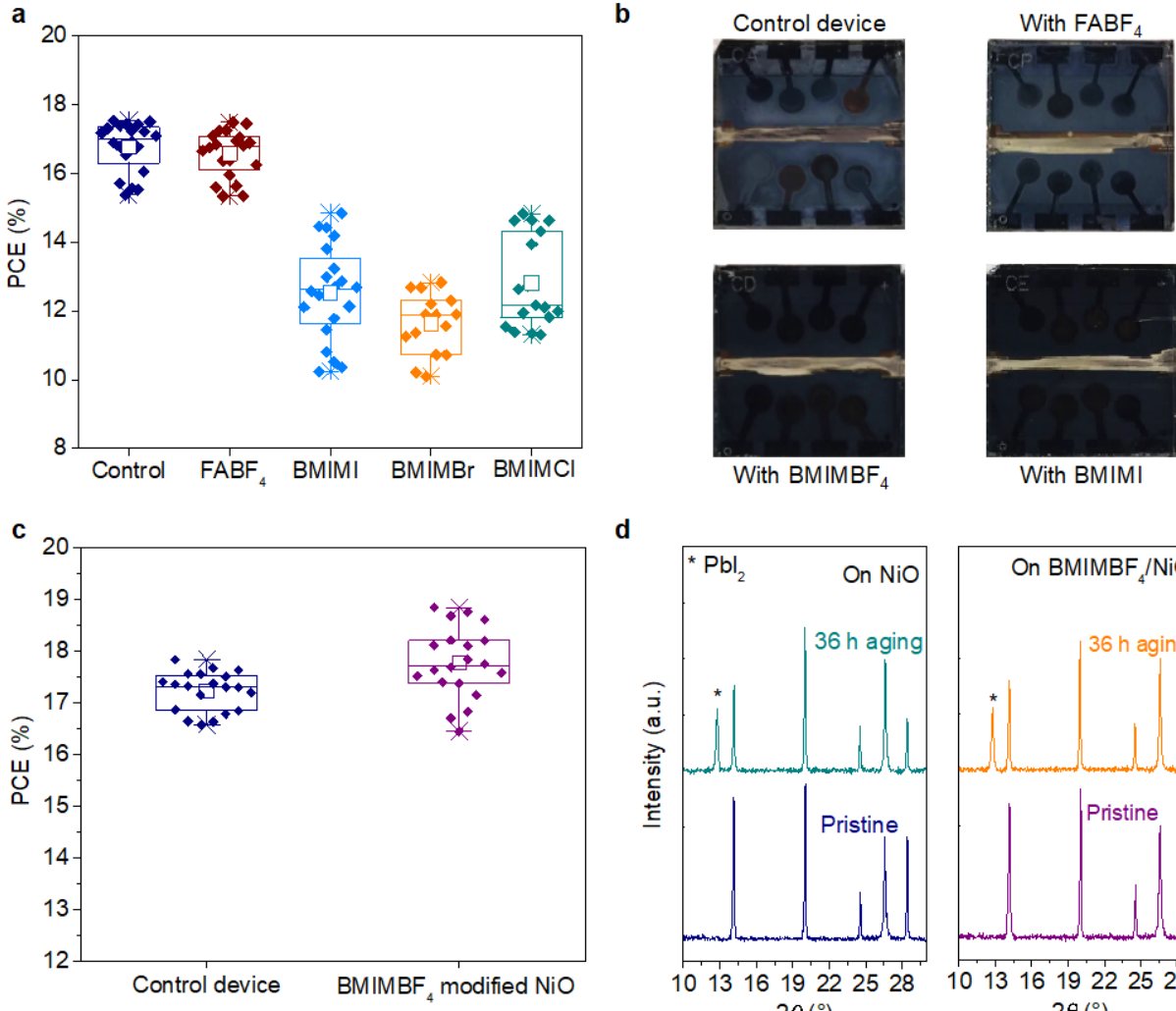

d
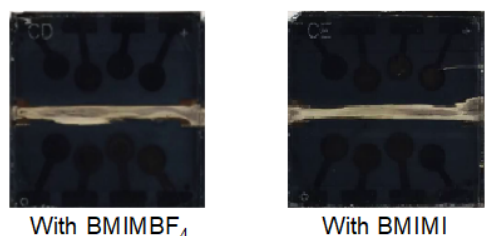

With BMIMI

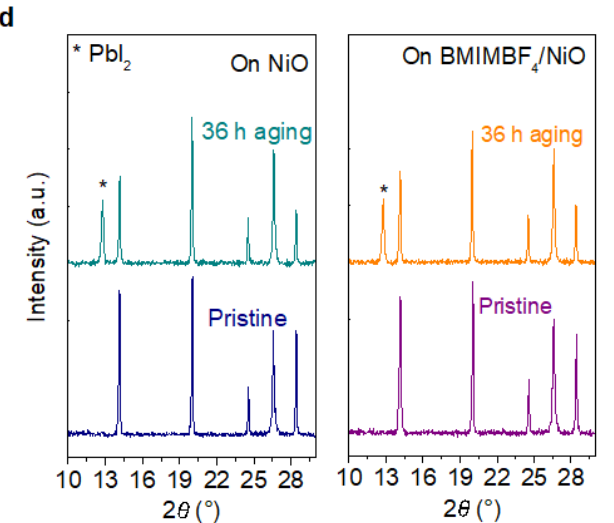

\section{Extended Data Figure $4 \mid$ Device performance and film stability with different ionic}

additive modifications. a, Statistics of PCEs of perovskite solar cells fabricated from precursors without and with different ionic additives $(0.3 \mathrm{~mol} \%)$ on $\mathrm{NiO} / \mathrm{FTO}$ substrates. $\mathbf{b}$, Photographs of the non-encapsulated control and devices with different ionic additives after $100 \mathrm{~h}$ aging under full-spectrum sunlight at $70-75^{\circ} \mathrm{C}$. c, Statistics of PCEs of perovskite solar cells fabricated on bare $\mathrm{NiO}$ and $\mathrm{BMIMBF}_{4}$ modified NiO. The PCEs are determined from FB-SC $J-V$ scan curves of 15 or more cells for each condition. The bottom and top star represents the minimum and maximum value, respectively; the open square represents the mean value and the box show the region containing $25-75 \%$ of the data. $\mathbf{d}$, XRD patterns of the fresh and aged perovskite films (under full spectrum sunlight at $60-65{ }^{\circ} \mathrm{C}$ in ambient air) without IL on bare $\mathrm{NiO}$ and on $\mathrm{BMIMBF}_{4}$ modified $\mathrm{NiO}$ substrates. 

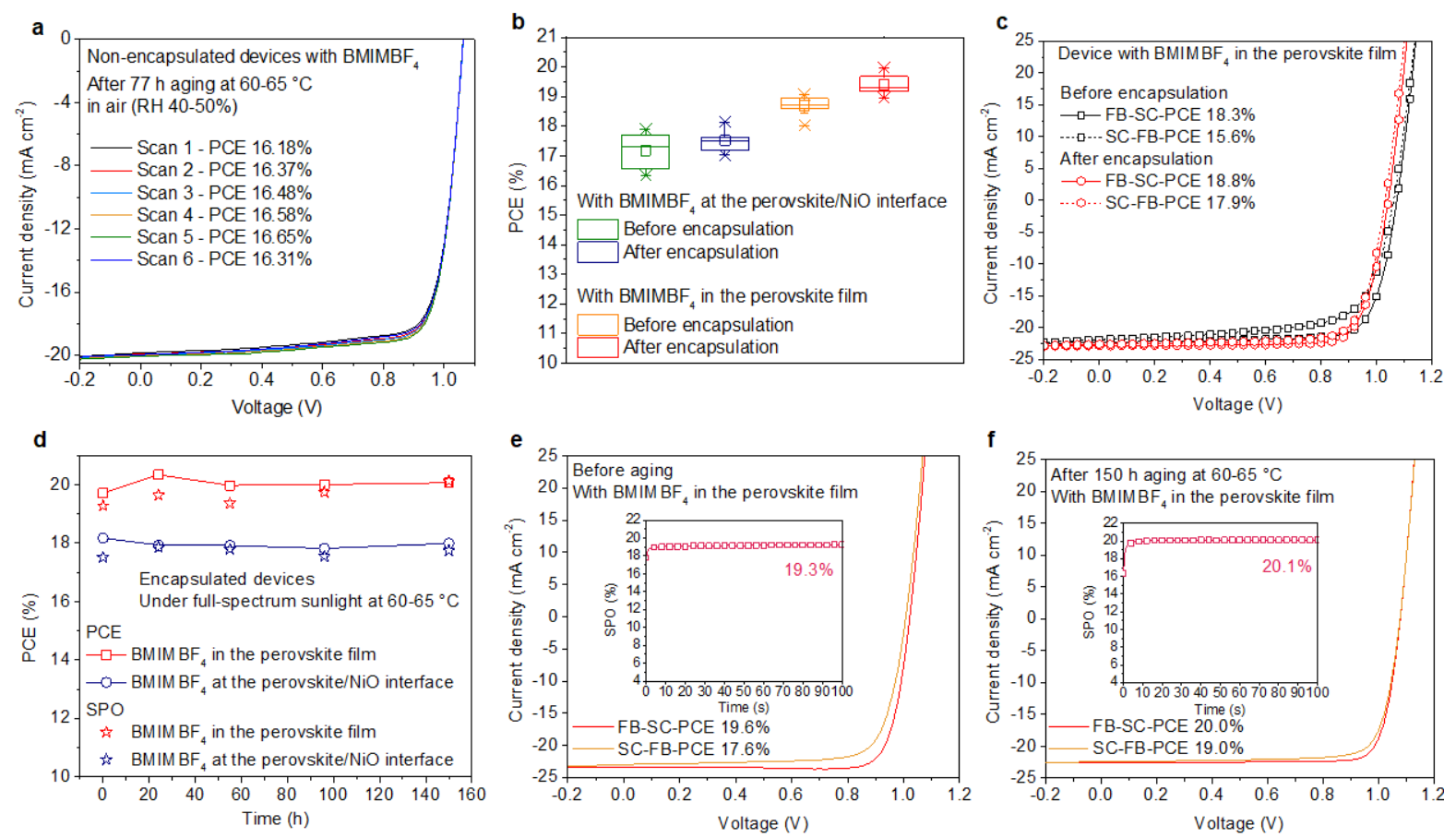

\section{Extended Data Figure 5 | Device stability performance under combined full-spectrum}

light and heat stressing. a, Light soaking during the $J-V$ measurement of non-encapsulated device with $0.3 \mathrm{~mol} \%$ in the perovskite layer after $77 \mathrm{~h}$ aging at $60-65{ }^{\circ} \mathrm{C}$ in air. $\mathbf{b}$, Statistics of PCEs of the devices before and after encapsulation. The PCEs are determined from FB-SC $J-V$ scan curves of 10 cells for each condition. The bottom and top star represents the minimum and maximum value, respectively; the open square represents the mean value and the box show the region containing $25-75 \%$ of the data. c, $J-V$ curves of one device based on $\mathrm{BMIMBF}_{4}$-containing perovskite film before and after the encapsulation. d, Device stability performance of solar cells with and without $\mathrm{BMIMBF}_{4}$ in the perovskite film under full-spectrum sunlight at $60-65^{\circ} \mathrm{C}$. e, f, $J-V$ and SPO curves of one high-performance device based on $\mathrm{BMIMBF}_{4}$-containing perovskite film before (e) and after (f) aging under full-spectrum sunlight at $60-65^{\circ} \mathrm{C}$. 

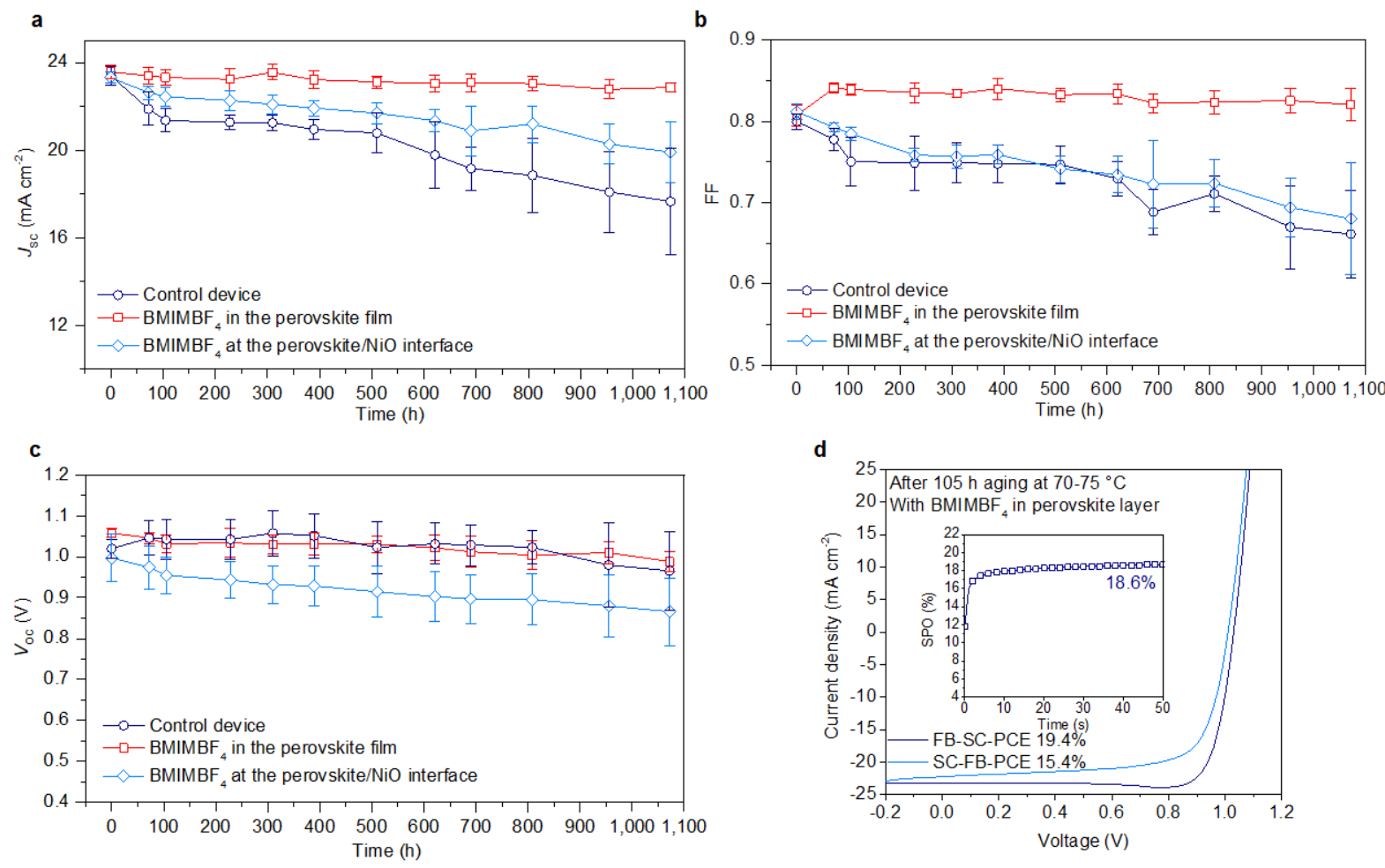

\section{Extended Data Figure 6 | Long-term device stability performance of a large set of} perovskite solar cells. a-c, Evolution of the device parameters of encapsulated perovskite solar cells, $J_{\mathrm{SC}}(\mathbf{a}), \mathrm{FF}(\mathbf{b})$ and $V_{\mathrm{OC}}(\mathbf{c})$ during the stability test under full spectrum sunlight stressing at $70-75{ }^{\circ} \mathrm{C}$. The average device parameter and the standard error (error bar) are calculated from 10 cells for devices with $\mathrm{BMIMBF}_{4}$ in the perovskite film (top 8 cells for the SPO) and 7 cells for the other two sets of devices (top 4 cells for the SPO), determined from the forward bias (FB) to short-circuit (SC) current-voltage $(J-V)$ scan curves. d, $J-V$ and SPO curves of one device with $\mathrm{BMIMBF}_{4}$ in perovskite film after $105 \mathrm{~h}$ aging under full-spectrum sunlight at $70-75^{\circ} \mathrm{C}$. 

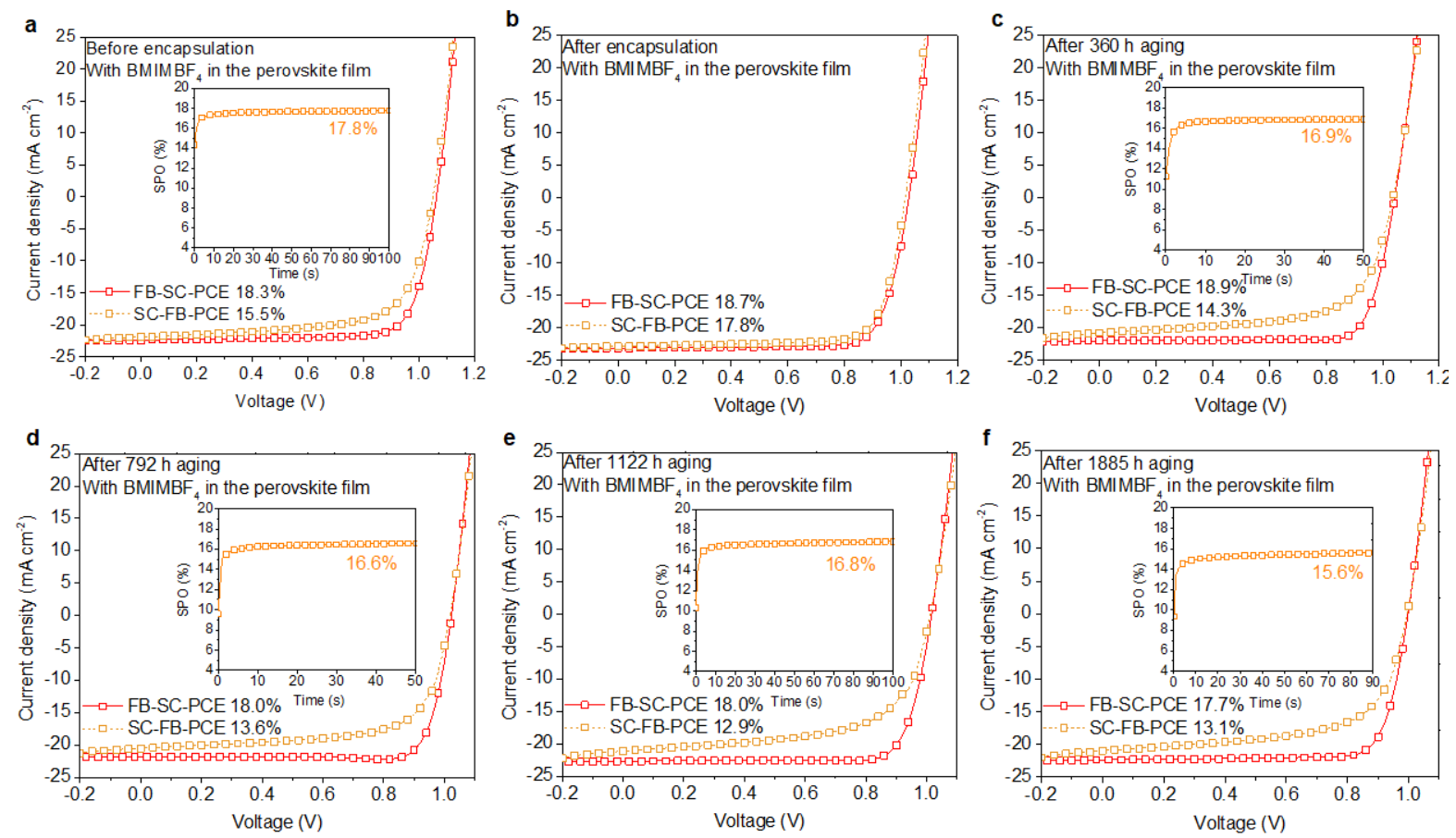

Extended Data Figure 7 Device performance of the most stable cell based on BMIMBF 4-containing perovskite film. a, $\mathbf{b}, J-V$ and SPO curves of the device before (a) and after encapsulation (b). c-f, Evolution of the $J-V$ and SPO curves during the long-term device stability test under full-spectrum sunlight at $70-75^{\circ} \mathrm{C}$. After aging for $360 \mathrm{~h}(\mathbf{c}), 792 \mathrm{~h}$ (d), $1122 \mathrm{~h}(\mathbf{e})$ and $1885 \mathrm{~h}(\mathbf{f})$. 

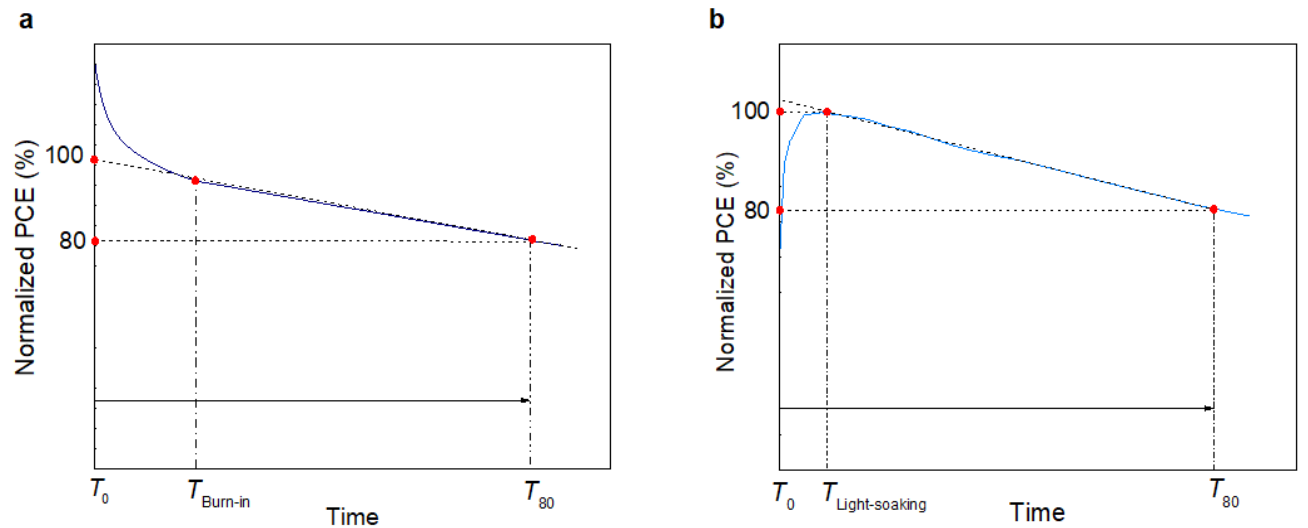

Extended Data Figure 8 Estimation methods of the $\boldsymbol{T}_{\mathbf{8 0}}$. a, For the devices with early "burn-in" effect, we fit the stability performance data after the "burn-in" section to a straight line, and extrapolate the curve back to zero time to obtain the $T=0$ efficiency. We then determine the lifetime to $80 \%$ of the $T=0$ efficiency as the $T_{80}{ }^{34}$. b, For the deices with positive "light-soaking" effect, we fit the stability data from the peak performance after the "light-soaking" section to a straight line. We calculate the lifetime to $80 \%$ of the peak efficiency and add the "light-soaking" time to obtain the total $T_{80}$ lifetime. 

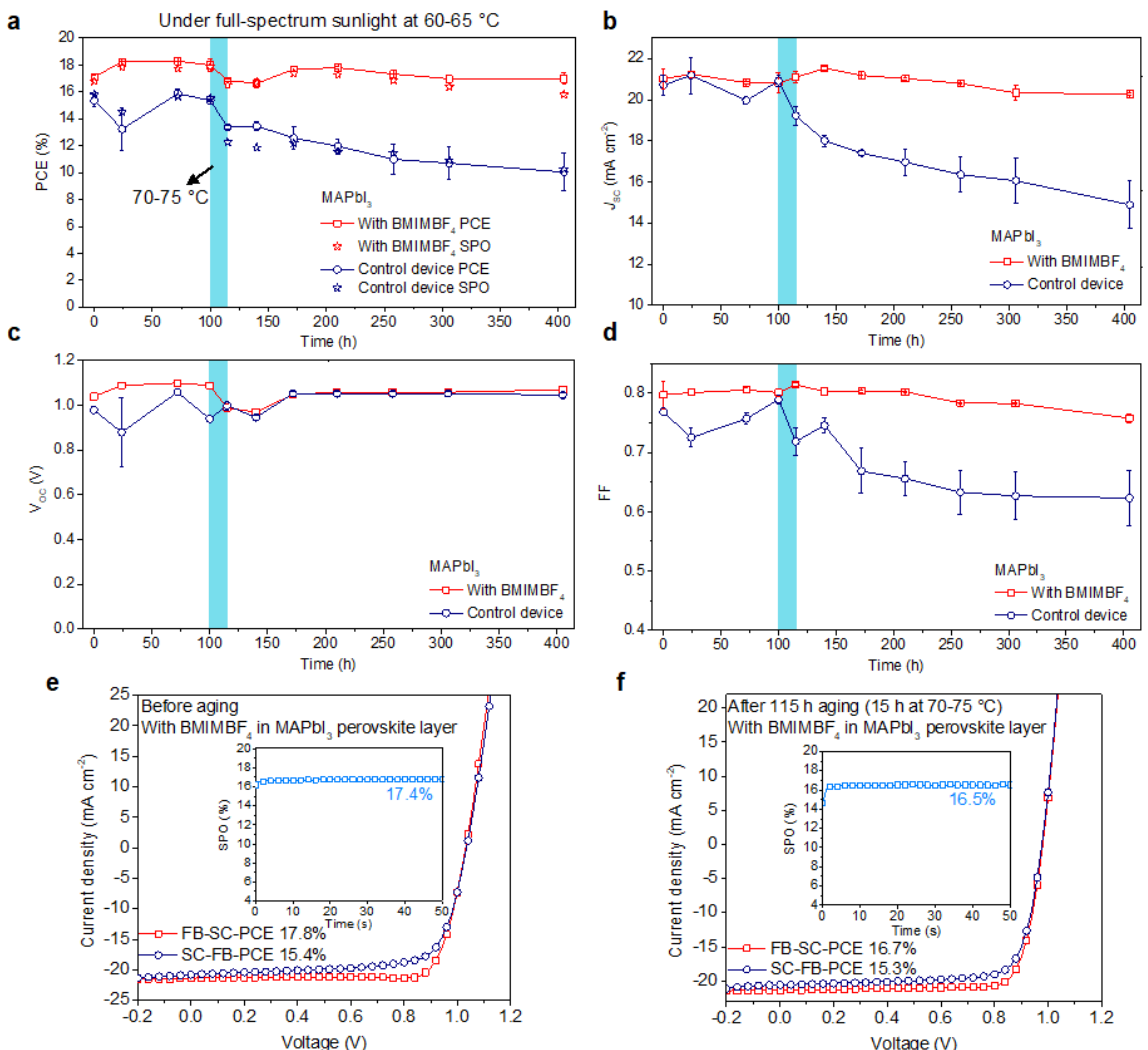

f

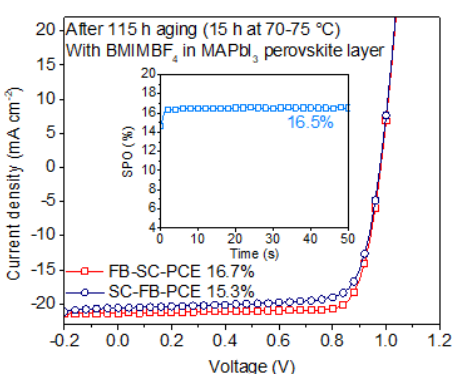

g

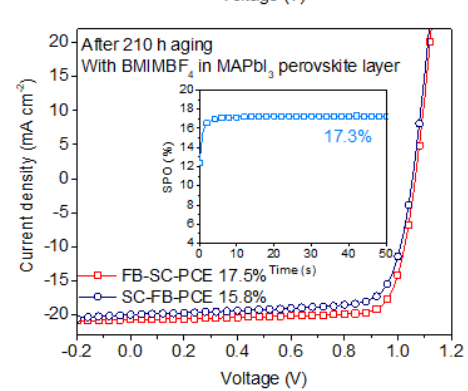

h

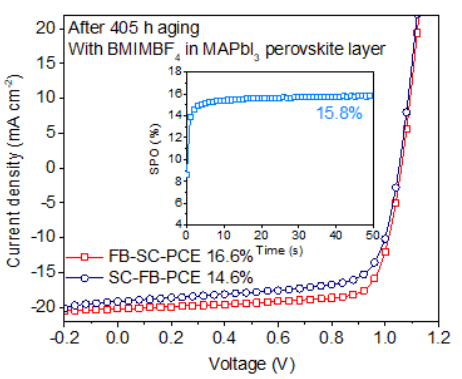

Extended Data Figure 9 | Operational stability of MAPbI3 solar cells under combined

light and heat stressing. a-d, Evolution of the device parameters during long-term device stability test under full-spectrum sunlight at $60-65^{\circ} \mathrm{C}$. PCE and SPO (a), $J_{S C}(\mathbf{b}), V_{O C}(\mathbf{c})$ and FF (d). The average device parameters and the standard error are determined based on peak $J-V$ scans from forward bias (FB) to short-circuit (SC) current-voltage $(J-V)$ scan curves of 2 and 3 different cells for devices with and without $\mathrm{BMIMBF}_{4}$ in the $\mathrm{MAPbI}_{3}$ perovskite film, respectively. During the region (100-115 h) marked as blue, the chamber temperature was increased to $70-75{ }^{\circ} \mathrm{C}$ to evaluate the device degradation behavior under increased elevated temperature. c-f, $J-V$ and $\mathrm{SPO}$ curves of the $\mathrm{MAPbI}_{3}$ device with $0.3 \mathrm{~mol}^{\circ} \mathrm{BMIMBF}_{4}$ in perovskite layer during the aging test for different time. Before aging (c), after aging for 115 $\mathrm{h}(\mathbf{d}), 210 \mathrm{~h}(\mathbf{e})$ and $405 \mathrm{~h} \mathrm{(f).}$ 


\section{Supplementary Tables}

Table S1. Detailed information of all chemicals used in this work

\begin{tabular}{|c|c|c|c|c|}
\hline Chemical & Supplier & Purity & CAS number & Product code \\
\hline Lead iodide $\left(\mathrm{Pbl}_{2}\right)$ & TCl Chemicals & $\begin{array}{l}99.99 \% \text { trace metals } \\
\text { basis }\end{array}$ & $10101-63-0$ & L0279 \\
\hline Lead bromide $\left(\mathrm{PbBr}_{2}\right)$ & Sigma-Aldrich & $\geq 98 \%$ & $10031-22-8$ & 211141 \\
\hline Formamidinium iodide (FAI) & $\begin{array}{l}\text { Greatcell Solar } \\
\text { Materials Pty Ltd }\end{array}$ & - & 879643-71-7 & MS150000 \\
\hline Cesium iodide (Csl) & Alfa-Aesar & $99.9 \%$ metal basis & $7789-17-5$ & 10022 \\
\hline Methylammonium iodide (MAI) & $\begin{array}{l}\text { Greatcell Solar } \\
\text { Materials Pty Ltd }\end{array}$ & - & $14965-49-2$ & MS101000 \\
\hline $\begin{array}{l}\text { Formamidinium tetrafluoroborate } \\
\left(\mathrm{FABF}_{4}\right)\end{array}$ & $\begin{array}{l}\text { Greatcell Solar } \\
\text { Materials Pty Ltd }\end{array}$ & 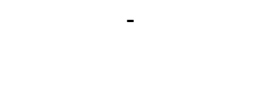 & - & MS550000 \\
\hline $\begin{array}{l}\text { 1-Butyl-3-methylimidazolium } \\
\text { tetrafluoroborate }\left(\mathrm{BMIMBF}_{4}\right)\end{array}$ & Sigma-Aldrich & $\geq 97 \%$ (HPLC) & $174501-65-6$ & 91508 \\
\hline $\begin{array}{l}\text { 1-Butyl-3-methylimidazolium iodide } \\
\text { (BMIMI) }\end{array}$ & Sigma-Aldrich & $99 \%$ & $65039-05-6$ & 713066 \\
\hline $\begin{array}{l}\text { 1-Butyl-3-methylimidazolium bromide } \\
\text { (BMIMBr) }\end{array}$ & Sigma-Aldrich & $\geq 97 \%$ (HPLC) & $85100-77-2$ & 95137 \\
\hline $\begin{array}{l}\text { 1-Butyl-3-methylimidazolium chloride } \\
\text { (BMIMCI) }\end{array}$ & Sigma-Aldrich & $\geq 98 \%$ (HPLC) & $79917-90-1$ & 94128 \\
\hline $\begin{array}{l}\text { poly[N,N'-bis(4-butylphenyl)-N,N'-bis( } \\
\text { phenyl)benzidine](Poly-TPD) }\end{array}$ & Lumtec & $\mathrm{MW}>10000$ (GPC) & $472960-35-3$ & LT-N149C \\
\hline $\begin{array}{l}\text { 2,3,5,6-Tetrafluoro-7,7,8,8-tetracyan } \\
\text { oquinodimethane (F4TCNQ) }\end{array}$ & Sigma-Aldrich & $97 \%$ & $29261-33-4$ & 376779 \\
\hline Nickel acetylacetonate $\left(\mathrm{Ni}(\mathrm{acac})_{2}\right)$ & Sigma-Aldrich & $95 \%$ & $3264-82-2$ & 284657 \\
\hline Hydrochloric acid $(\mathrm{HCl})$ & Sigma-Aldrich & 36.5-38\%, Bioreagent & $7647-01-0$ & $\mathrm{H} 1758$ \\
\hline $\begin{array}{l}\text { [6,6]-phenyl-C61-butyric acid methyl } \\
\text { ester (PCBM) }\end{array}$ & Solenne BV & $>99.5 \%$ & $160848-22-6$ & 060995 \\
\hline Bathocuproine (BCP) & Sigma-Aldrich & $\begin{array}{l}99.99 \% \text { trace metals } \\
\text { basis }\end{array}$ & $4733-39-5$ & 699152 \\
\hline
\end{tabular}

